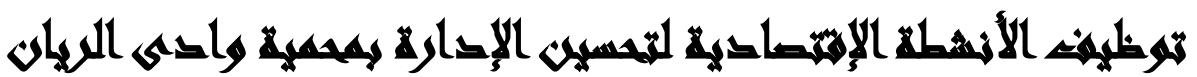

[1^]

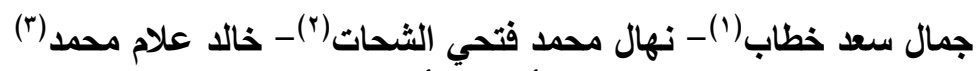 \\ دعاء أبو بكر أحمد أندات
}

( ) كلية التجارة، جامعة عين شمس r ) معهة الدراسات والبحوث البيئية، جامعة عين شمس أبمس

\section{المستحلت}

هدف هذا البحث إلى التعرف على كيفية استخدام الأنشطة الإقتصادية لتحسين الإدارة

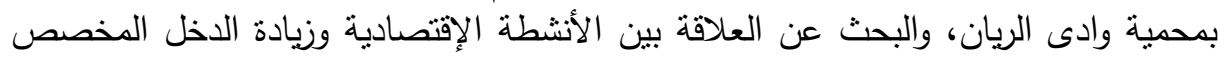

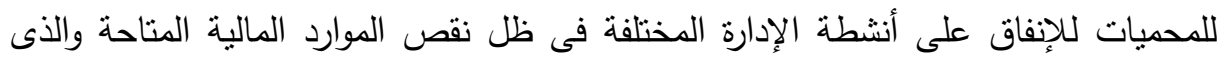

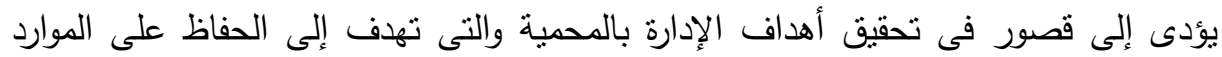

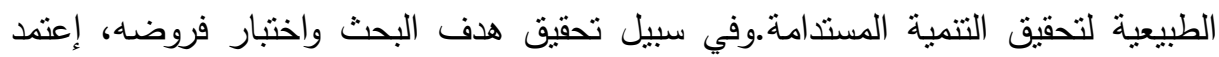

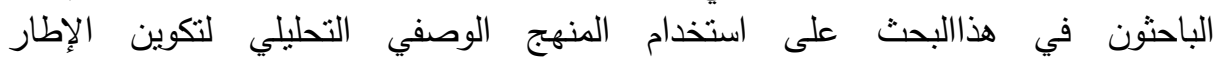

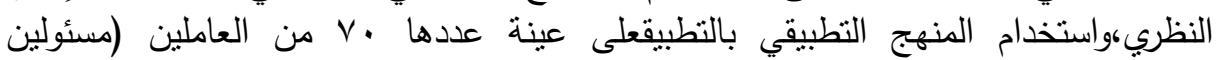

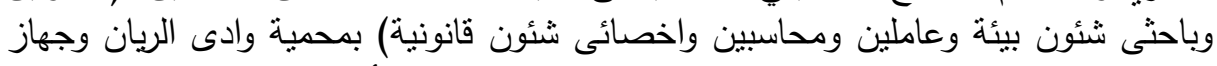

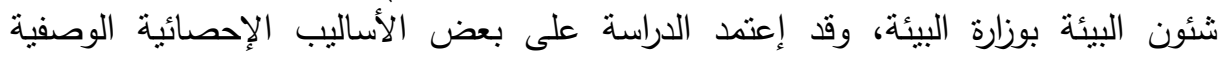

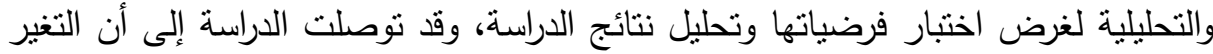

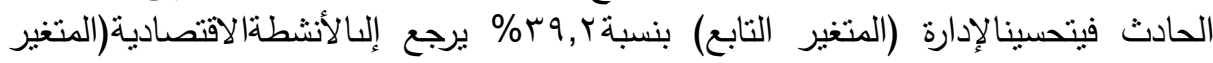

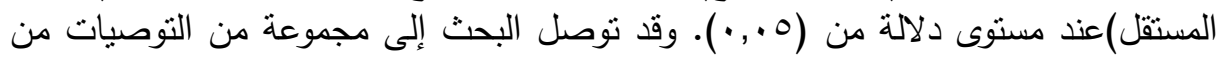

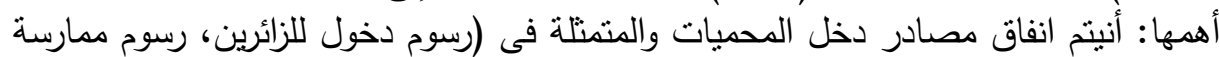

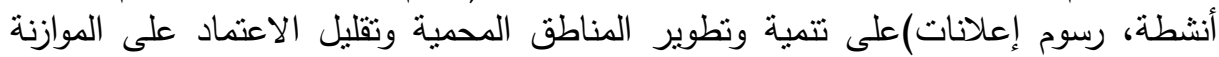

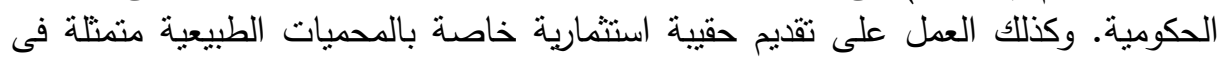

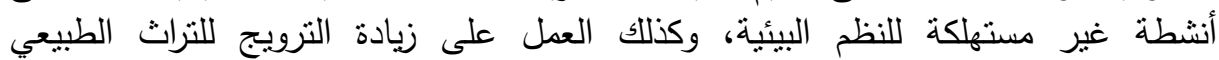

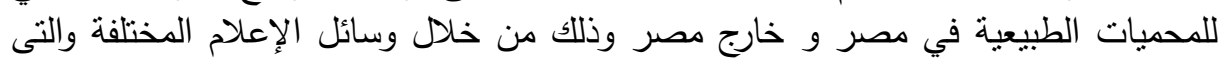

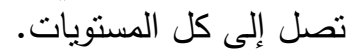

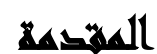

إن الدول النامية على مستوى العالم لديها تحديات ضخمه وهى محاولة صون الطبيعة وكذلك الحفاظ على الموارد الناضبة وتتضح هذه التحديات من خلال وجود ضرول ضروريات ملحه

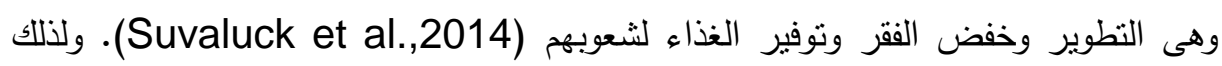

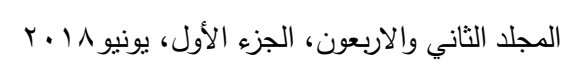


زادت السياسات ومستوى الاجراءات المتبعه من الحكومات لصون الطبيعه وبالتالى زيادة الإنفاقالحكومي على صون الطبيعة وخفض الفاقد فى الموارد الطبيعية. وتتعنبر القيمةالاقتصادية للمورد الطبيعي من الأمورالهامةالتي زاد النظر إليها فى الآونة الاخيرة من فئه قبل متخذ القرار .( (Deborah et al.,2014). وتمثل المحميات الطبيعية أداة رئيسية نستخدم عالميا من أجل حماية الموارد الطبيعية وحتى تكون بمثابة حاجز ومأوى في وجه الاتجاه المتزايد للآثار البشرية.إن الهدف من التهيه التمية المستدامة للموارد الطبيعية لا يمكن تحقيقه بالتحكم والعقوبات الحادة ولكن من خلال تشجيع

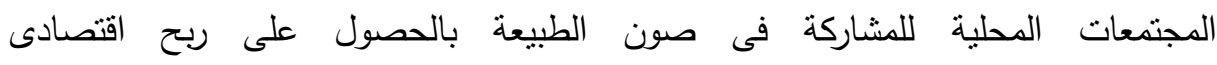
مباشر .(Chun.,et al.,2013). في حين نركز البلدان على حماية المناطق الطبيعية الرائعة

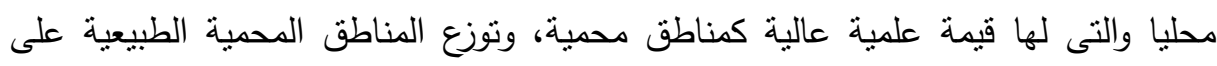
نطاق واسع في جميع أنحاء العالم، وتغطي جميعها مساحة كبيرة. هذه التغطية واسعة تساهم إلى حد كبير في الحفاظ على البيئة الطبيعية العالمية. (Masaaki Yui, 2014). إن الموقع الاستراتيجى لمصر عند تلاقى القارات الثلاث بموائله الارضيه والبحريه يدعم لئه

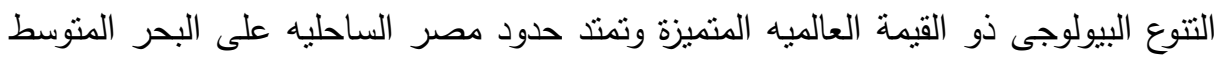

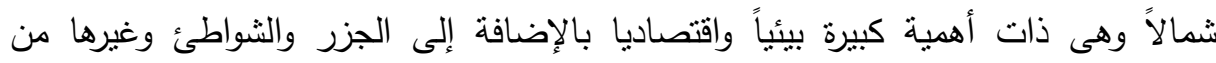
المناظر الطبيعيه التى تدعم بقوة التتوع البيولوجى المصرى.وتؤدى المحميات الطبيعية دورا

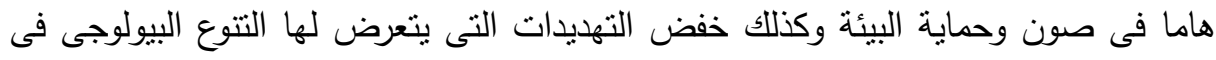
مصر (EEAA,2010)

\section{And}

إن عدد ومساحة المناطق المحمية فى العالم قد توسعت بشكل كبير في العقود الأخيرة.

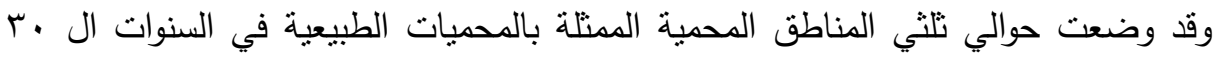
الماضية. وخلال الفترة نفسها كان هناك زيادة كبيرة أيضاً في عدد من البلدان النى اعلنت المحميات الطبيعية كوسيلة لحماية البيئة. (EEAA,2014). يعتبر التمويل أحد الركائز الرئيسة لجهود الحماية. وحيث أن المصادر المالية المتاحة للمحميات الطبيعية فى العالم 416

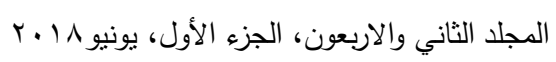


لاتكفى إلا نسبة ضئيلة من احتياجاتها اللازمة لتحقيق ادارة فعالة للموارد الطبيعية. هذا الفارق المادى الكبير ينعكس سلباً على نوعية أنشطة الحماية المنفذة، كما يؤثر جذرياً على لهاتئه

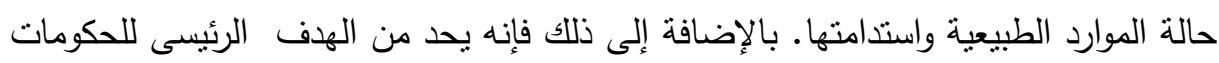
والمتمنل فى رفع مستوى المعيشة(A. Abdrabo, 2015). إن تحدى الإدارة الرئيسى هو ضعف مستوى التمويل والتتسيق بين الجهات التى نتشرك

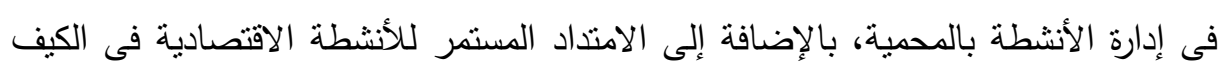

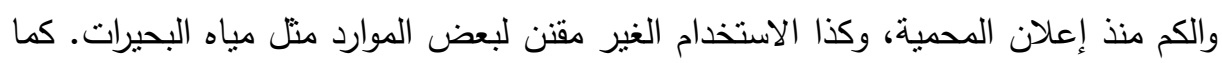

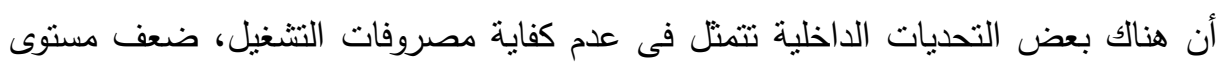
التدريب للكوادر (EEAA, 2008).ما إمكانية توظيف الانشطة الاقتصادية لتحسين الإدارة بمحية وادى الريان بويمكن تجزئة السؤال السابق إلى:

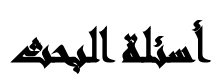

• ما إمكانية تعظيم دور الأنشطة الإقتصادية بمحية وادى الريان لتدعم أنشطة الإدارة فى

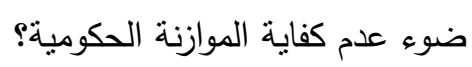

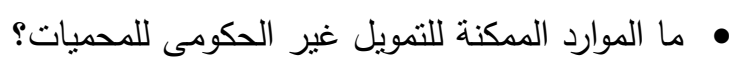

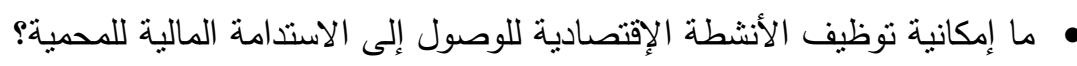

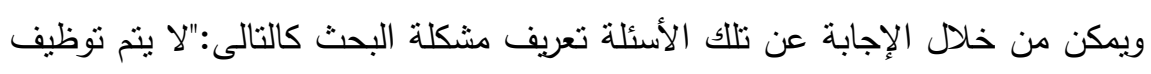
الأنشطة الاقتصادية بالمحميات كمصدر للاخل غير الحكومى فى ضوء الإبة عدم كفاية الميزانية

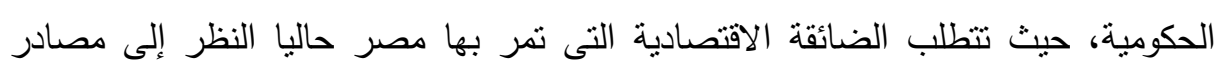
غير تقليدية لدعم الدحميات الطبيعية بها".

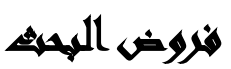

فى ضوء مشكلة البحث وأهميتها وتحقيقاً لأهدافها يسعى الباحثون إلى اختبار الفروض التالية: • الفرض الأول: يوجدعلاقة ارتباط معنوية للأنشطة الاقتصادية و تحسين الإدارة.

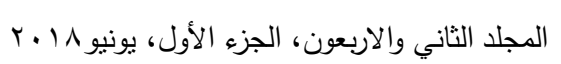


• الفرض الثانى: نوجد فروق معنوية ذات دلالة إحصائية في منوسط استجابات العاملين نحو إدراكهم لأهمية الأنشطة الاقتصادية وفقا للخبرة الوظيفية والمستوى الوظيفي.

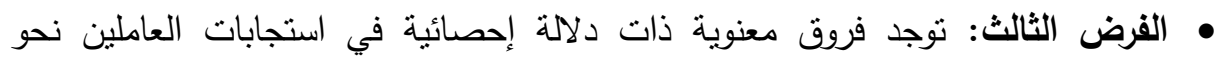
إدراكهم أهمية تحسين الإدارة وفقا للخبرة الوظيفية والمستوى الوظيفي.

\section{ألهan}

• يتتاول هذا البحث إمكانية تعظيم دور الأنشطة الإقتصادية بمحمية وادى الريان لتدعم أنشطة الإدارة فى ضوء عدم كفاية الموازنة الحكومية. • • تحديد الموارد الممكنة للتمويل غير الحكومى للمحميات. • استخدام الأنشطة الإقتصادية للوصول إلى الاستدامة المالية للمحمية نركز الدراسةعلى غيلى بعض المتغيرات المهمة المرتبطة بالثقافة البيئية.

\section{أهساهي المهند}

الهدف الأساسي للبحث هو محاولة إستخدام الأنثطة الاقتصادية لتحسين الإدارة بالمحمية ويتحقق من خلال الأهداف الفرعية التالية: • عصر وتصنيف الأنشطة الإقتصادية الموجودة بمحية وادى الريان.

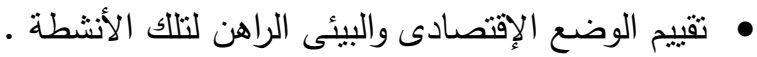
• توصيف المشكلات البيئية بالمحمية وأسبابها من خلال البيانات الفعلية بالمحمية.

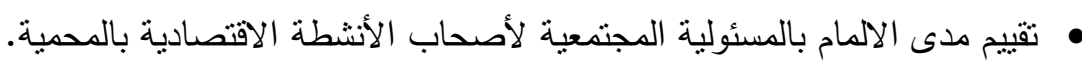
• تقديم بعض الأمنلة لأنشطة إستثمارية ملائمة للعمل داخل المحمية.

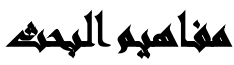

المحميات الطبيعية: يعرف الاتحاد الدولي لصون الطبيعة (IUCN) المناطق المحمية

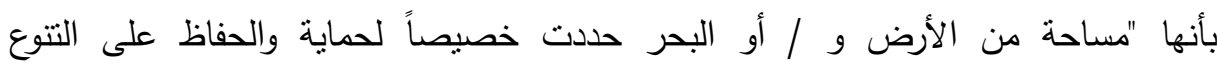


البيولوجي، والموارد الطبيعية والثقافية المرنبطة بها، وتدار من خلال إطار قانونى أو غيرها من التدابير الفعالة) (IUCN 1994a)

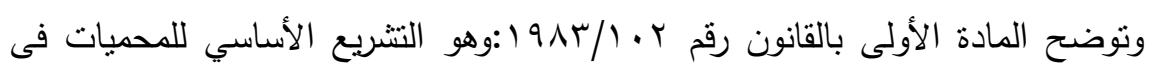

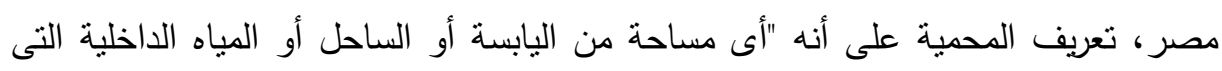

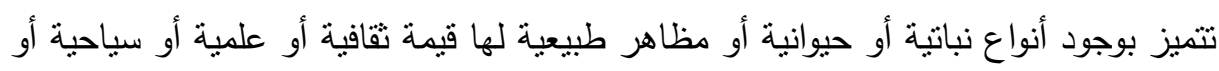

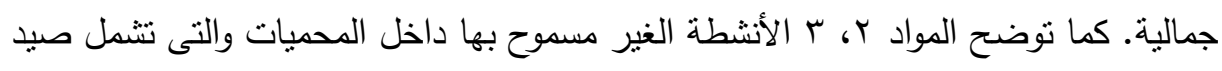

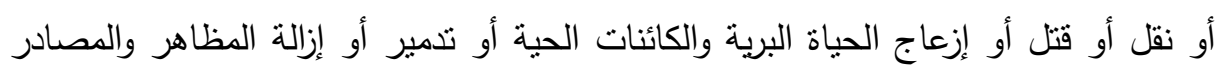

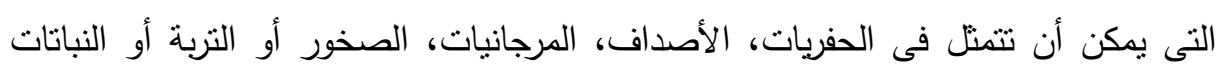

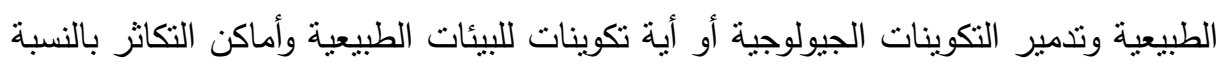
للحيوانات أو النباتات.

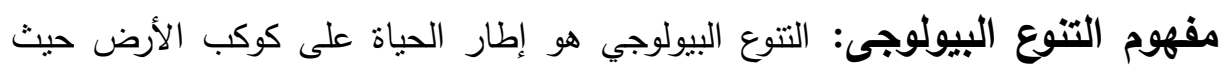

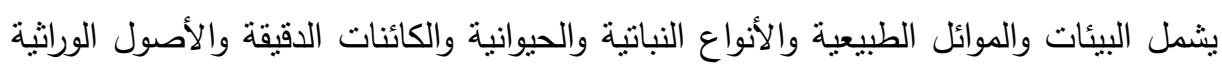

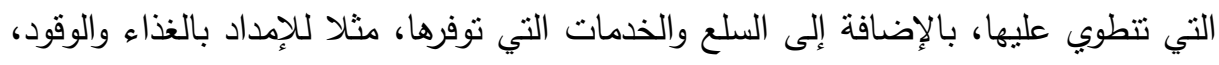

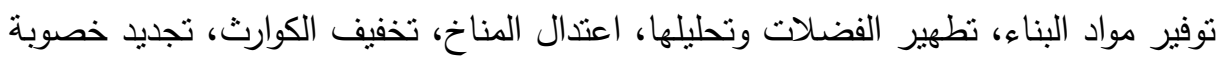

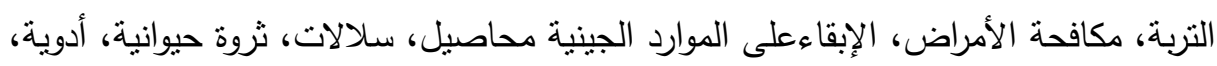

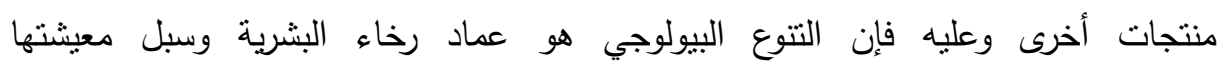

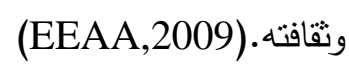

\section{السراساهي الماريهن}

داساسة (Mohamed et al.,2015): هدفت الدراسة تقييم الهنافع والتكاليف المرتبطة

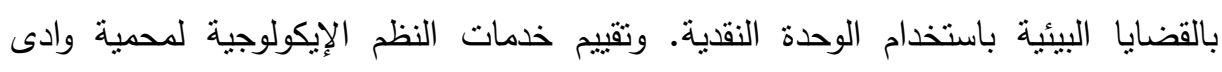

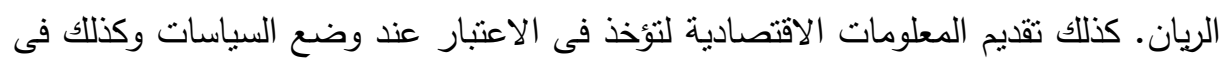

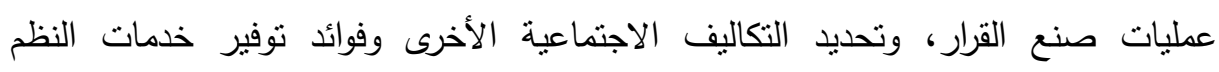

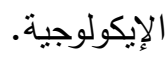

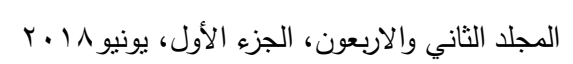


دراسةة: هذه الدراسة هي محاولة لتقييم فعالية الإدارة من خلال اتفاقيات الثراكة الاقتصادية والاتفاقيات البيئية، باستخدام التحكم وتقليل الأنشطة التي تسبب تنآكل وفقدان السواحل. والسيطرة وتقليل الأنشطة التي تسبب النلوث على طول المناطق الساحلية. وخلصت الدراسة إلى أن التغير في استخدام الأراضي. من حيث المساحة ونسبة التغير في نوعية الأراضي لوني

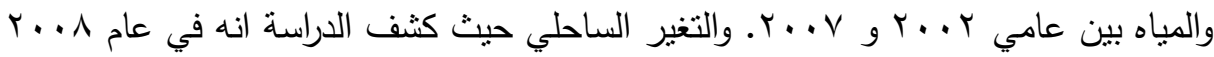
ما يصل إلى ץ, ؟ء في المائة من طول الساحل الكلي قد نم نقله إلى هياكل خرسانية وكذلك التغير فى جودة المياه. دراسة (Deborah et al.,2014): هدفت الدراسة إلى تسليط الضوء على الاستعداد للافع

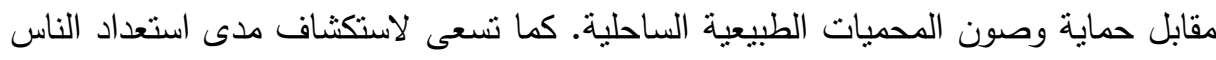

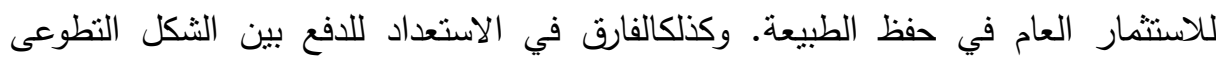
الفردى والثكل الالزامى الجماعى. (الن. دراسة (حازم، 17 ـ ب): هدفت الاراسة الى دراسة العلاقة بين زيادة الاستثمار فى قطاع

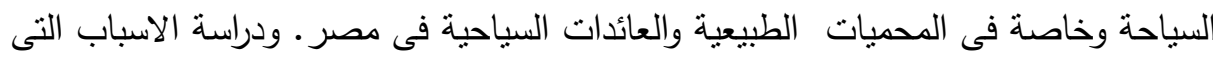
تؤدى الى قلة عدد السائحين الوافدين الى مصر.دراسة امكانية تطوير قطاع السياحة عامة والمحميات الطبيعية خاصة.دراسة اهمية قطاع السياحة للاقتصاد المصرى. ومن خلال الدراسة الاستقرائية للاراسات السابقة تم تحديد أوجه الاتفاق والاختلاف: • الدراسات المختلفة التى طبقت على المحميات الطبيعية كانت تهتم بدراسة العلاقة بين زيادة الاستثمار فى قطاع السياحة والعائدات السياحية فى مصر . وكذلك تحديد الانشطة

السياحية التى تمارس داخل المحميات وأى منها له تأثثر سلبى على الموارد الطبيعية.

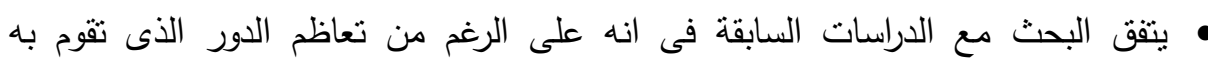

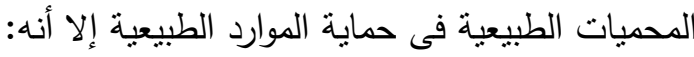

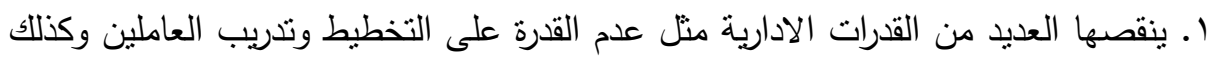
نقص الإمكانيات البشرية. 
r. التنسيق بين جهاز شئون البيئة والقطاعات والوزارات المختلفة فيما يتعلق بالقرارات الخاصة بالاستثمارات التى تتم بالمحميات الطبيعية. r. يعتبر التمويل أحد الأعمدة الرئيسية لجهود الصون بومن دوات باتئى الأسف أن المصادر المالية المتاحة للمحميات الطبيعية فى العالم لا تكفى إلا نسبة ضئيلة من احتياجاتها لإئه المادية.

لم يجد الباحثون من بينها دراسة تصدت لدراسة العلاقة بين الأنشطة الأقتصادية وتحسين

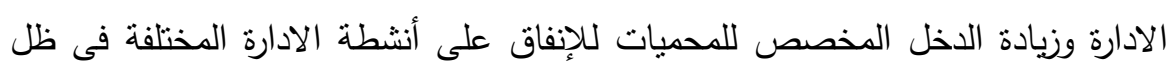
عجز الموازنة الحكومية والذى يؤدى الى قصور فى تحقيق أهداف الإدارة بالمحميات لتحقيق التتمية المستدامة.

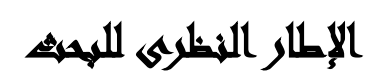

أولاً: محمية وادى الريان: وتقع محمية وادى الريان فى الجزء الجنوبى الغربى من الفيوم،

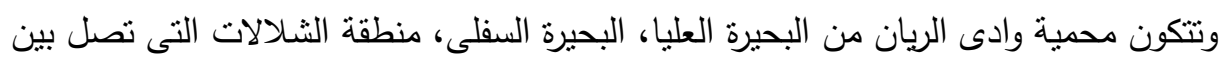

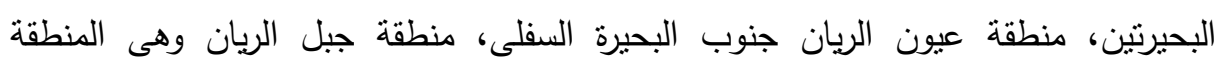

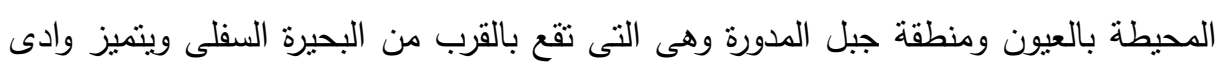

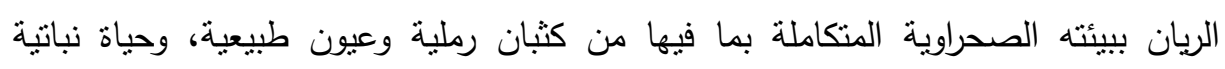

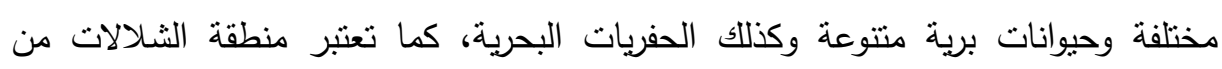
مناطق الرياضات البحرية المختلفة، وبالمحية 10 نوعا من الحيوانات البرية، أهمها : الغزال الأبيض، الغزال المصري، ثعلب الفنك، ثُعلب الرمل وتوجد بالمحمية أنواع مختلفة من الطيور

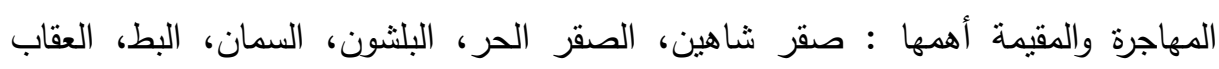

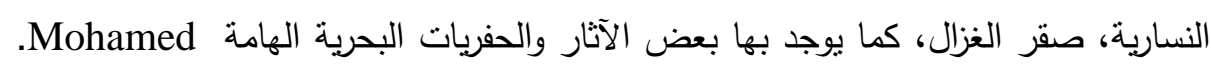

A. Abdrabo,(2015) 
وصف عام للمحمية:

1- بحيرات الريان: (البحيرة العليا والبحيرة السفلى والقناة الموصلة بينهما) تشكلت بحيرات

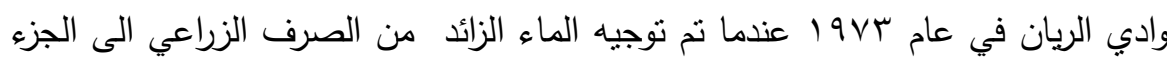

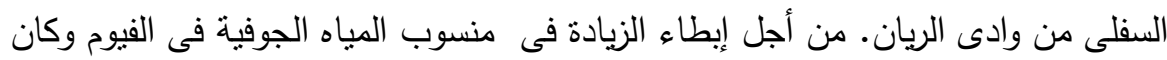

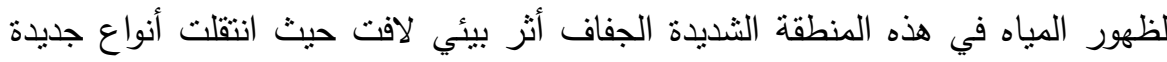
من الثييات والطيور واللافقاريات والنباتات إلى منطقة وادي الريان و كذللك خلق بيئات تكاثز الأسماك.

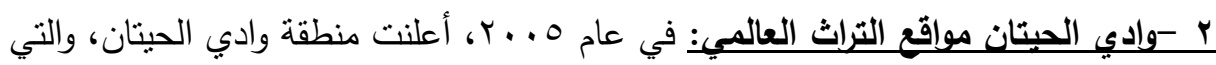
تقع داخل المحمية، من قبل اليونسكو كأول موقع للتراث الطبيعي مصرى عالمي، وذللك

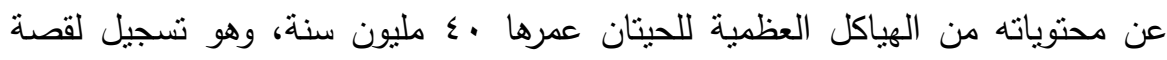
تطور الحيتان (من حيوانات تعيش على الأرض إلى حيوانات تعيش فى المحيط). ووفقا

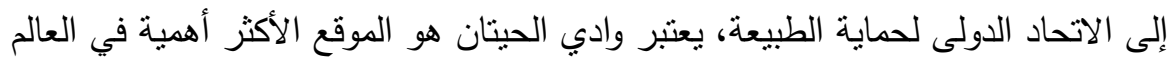

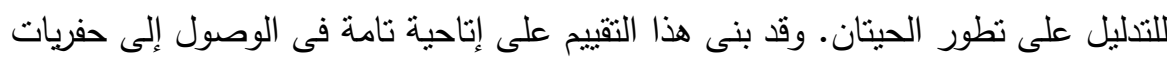

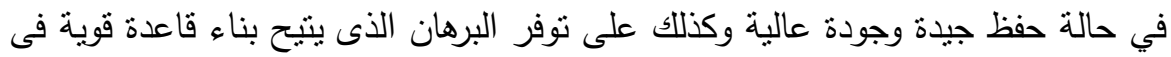

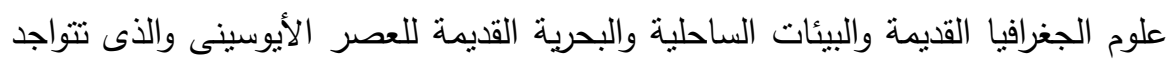

فيه تلك الحفريات. (Mohamed A. Abdrabo,(2015) ب -الثلالات: وتقع في منطقة الزيارة الرئيسية، هي واحدة من مناطق الجذب الأكثر شعبية

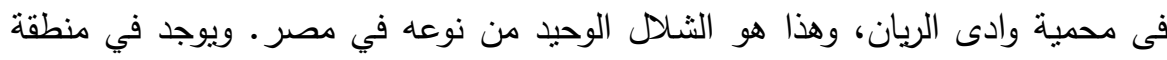

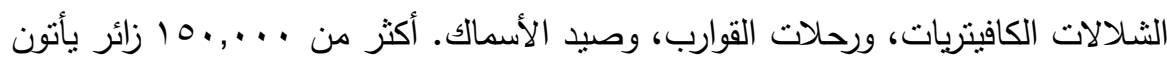

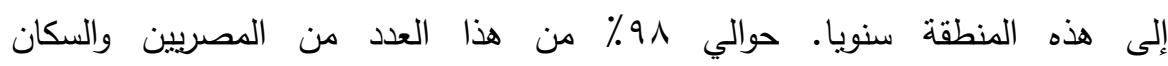
(Mohamed A. Abdrabo,(2015). المحليين ع-منطقة العيون: تحنوي المنطقة أربعة ينابيع للمياه والتى تقدم دعم لنتوع النباتات

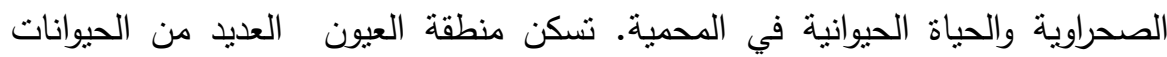
النادرة والمهددة عالميا بالانقراض، بما في ذلك الغزال المصرى وتعلب الفنك وثنطب الرمال 
وغيرها. انها تمنل البقايا الأخيرة من البيئات الطبيعية فى منخفض وادي الريان كما تعتبر واحة صحراوية غبر مأهولة.

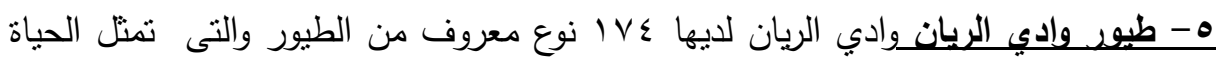

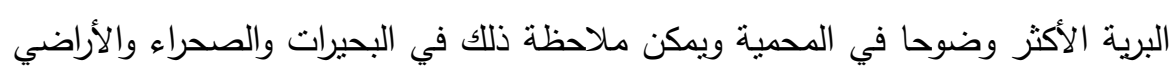

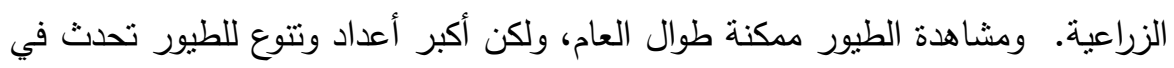
فصل الثتاء عندما تكون البحيرات تعج بالطيور المائية المهاجرة. وقد نم إعتبارها من قبل اعنل

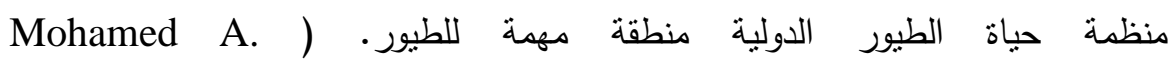
.(Abdrabo, $(2015$

\section{ثانياً: الأنشطة الاقتصادية بالمحمية وتأثيراتها البيئية:}

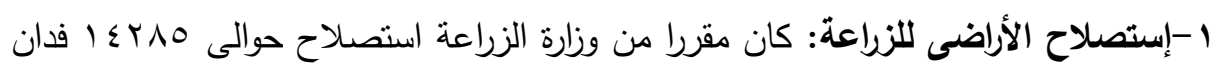

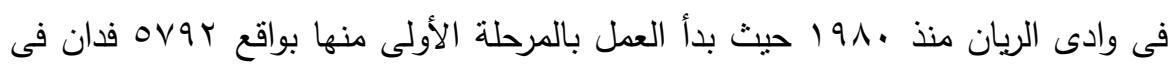

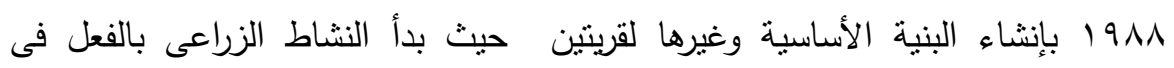

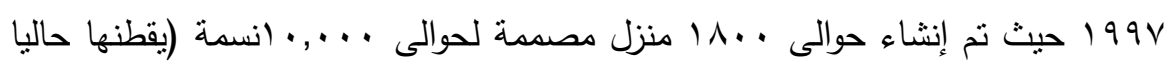

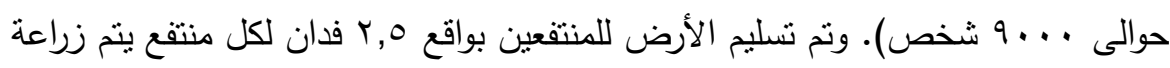

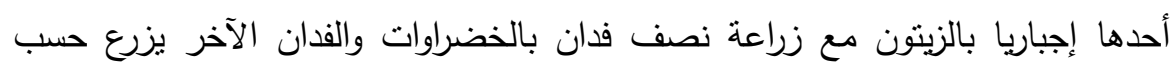

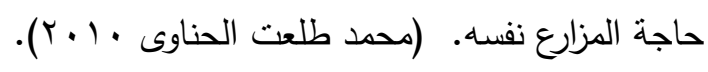

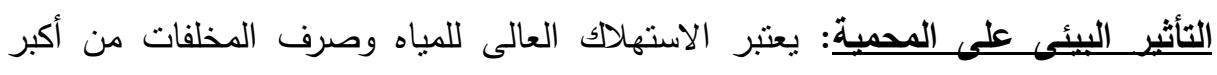
التأثيرات البيئية الحالية وتغيير شكل الأرض للصحراء الغير مأهولة إلى الأرض المزروعة الألئ المأهولة • التأثير على التتوع الحيوى هو أعلى التأثيرات البيئية المستقبلية حيث يتمثل فى التأثير

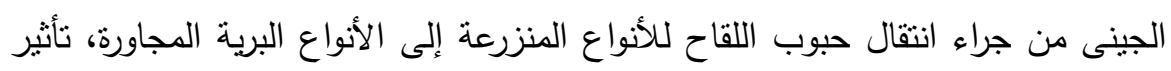

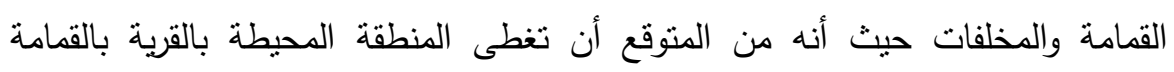
المتطايرة وبالذات تلك المخلفات غير المتحللة متل الأنواع البلاستيكية. 
هيتوقع امتلاء قنوات الصرف الزراعى خلال الفترة القادمة، حيث أنه من المتوقع وصول التصريف إلى البحيرة السفلى بواقع • ب بّ والتى سنكون محملة بالملوثات السامة (مبيدات الآفات والعناصر الثقيلة) والعناصر المغذية. ل(محمد طلعت، • ( • r). r - محطة الرفع: وهى الدحطة المقامة على البحيرة الأولى لرفع المياه إلى منطقة

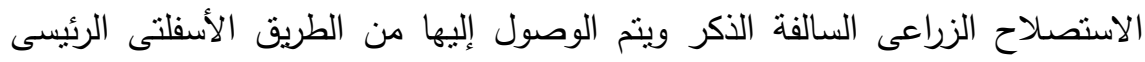

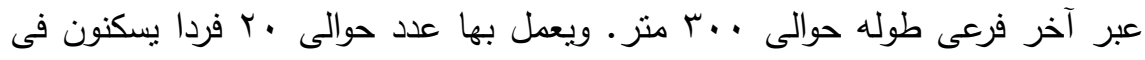
مقر شركة مساهمة البحيرة خارج المحمية. التأثثر البئي على المحمية: تعتبر القمامة والمخلفات الناتجة عن عمليات الإصلاح والصيانة

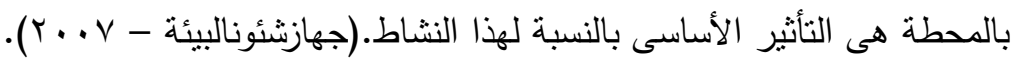

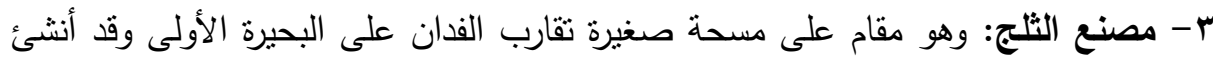
لتصنيع رقائق التلج (بمصدر مائى من البحيرة الأولى) بطاقة مستمدة من

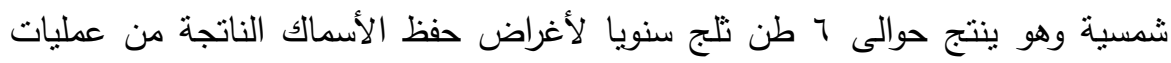

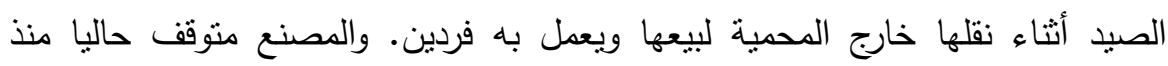

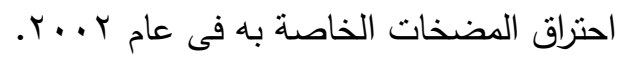

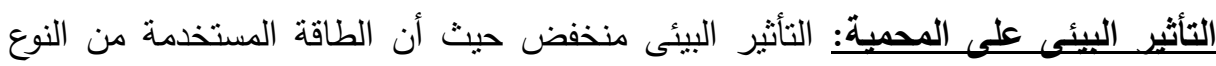
النظيف (خلايا شمسية) كما أن عدد الأفراد المقيمين يوميا هو واحد فقط للحراسة. (محمد

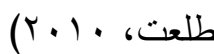
ع -الدير القبطى: استوطن مجموعة من الرهبان القبطيين جزء من منطقة العيون الطبيعية بمحمية وادى الريان. كما استجلبوا مجموعة من العمال لإعادة نهيئة 11 كهف كانت

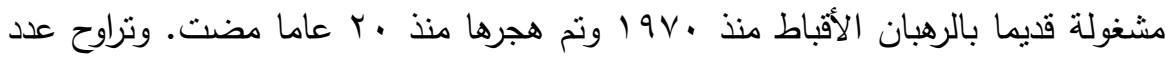
الرهبان ما بين النقص والزيادة حتى وصل حاليا إلى حوالى ·ـ فرد يعيثون بصورة دائمة فى الدير • والدير مزود بخزانات التحليل اللازمة للصرف الصحى وكذللك هناك نظام لجمع القمامة حيث يعاد استخدام المخلفات القابلة للتحلل وحرق غير القابلة للتحلل. ويشمل الدير العناصر التالية من البنية الأساسية: 


$$
\text { - عدد حوالى ·r راهب مقيم }
$$

• ( أكثر من •0 مغارة (كهف)

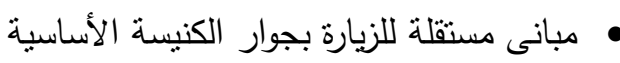

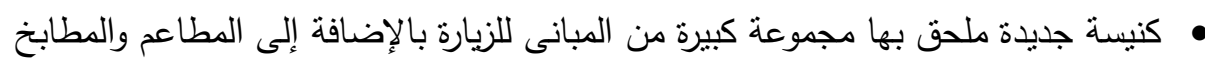

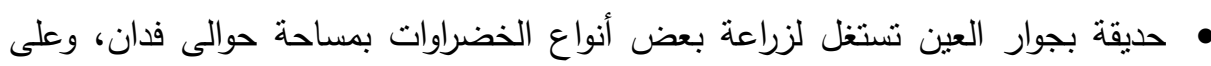

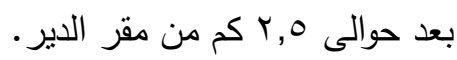

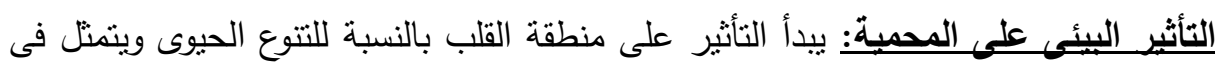
الإزعاج المباشر للحياة البرية الموجودة وذلك من تكرار دخول السيارات لتلبية احتباجات الرهبان من المأكل والمشرب.

نم زراعة حوالى فدان بالخضراوات المختلفة (زادت فى الوقت الحالى إلى خمسة أفدنة تقريبا) بجوار إحدى عيون المياه والتى تهدد فعليا التتوع الحيوى وتغير أنماط التغذية للحيوانات البربية بالمنطقة.

الاستهلاك العالى لمياه العين المحدودة، مما أثز على مياه العين المجاورة وأدى إلى بلى

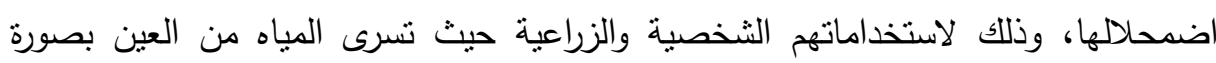

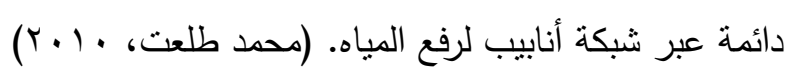

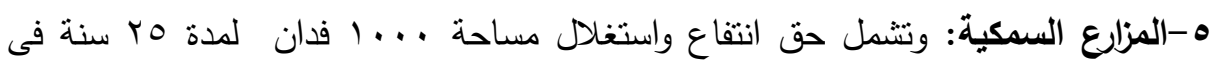

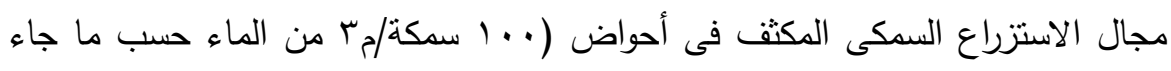

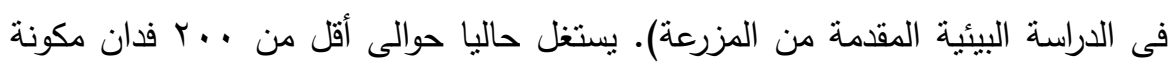

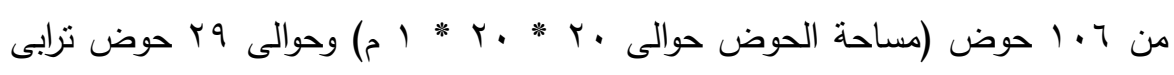

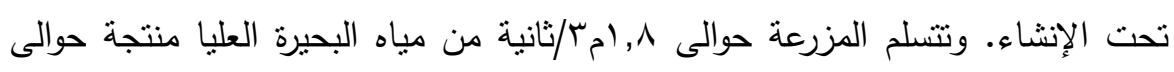
•

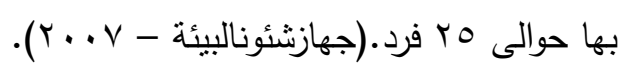

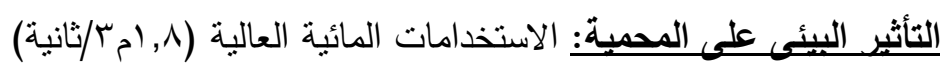

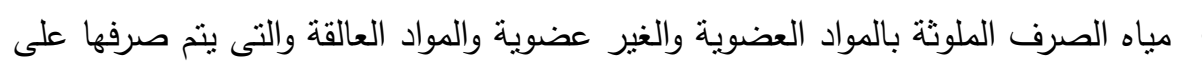
القناة الموصلة بين البحيرتين. 
• تشويه المنظر الطبيعى للمنطقة والممثل فى النفايات والقمامة ومولدات الطاقة الكهربية وانبعاثاتها

צ-الجمعية التعاونية للاستزراع السمكى: ويشمل استغلال مساحة . . با فدان لمدة Oب سنة

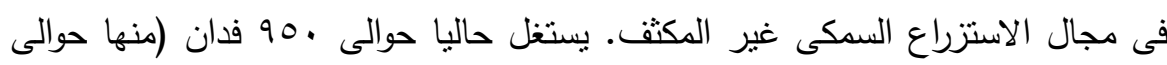
•

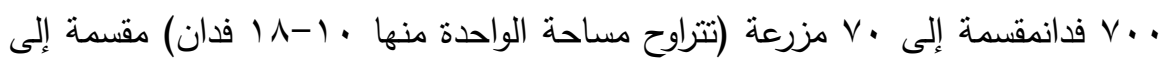

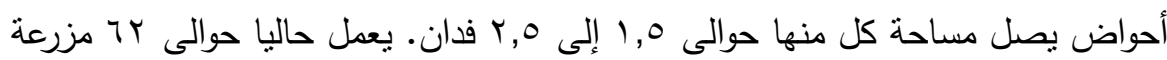

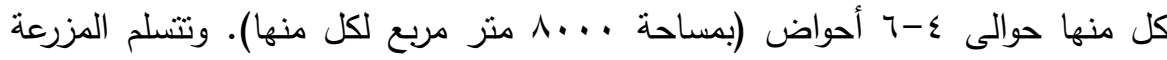
تصريفا من مياه البحيرة الأولى يصل إلى بامس/ثانية تقريبا. وتتشمل أنواع الأسماك

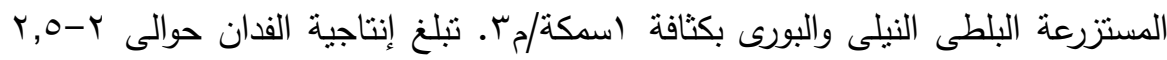
طن سنويا مما بعنى حوالى ... T أطن سنويا.

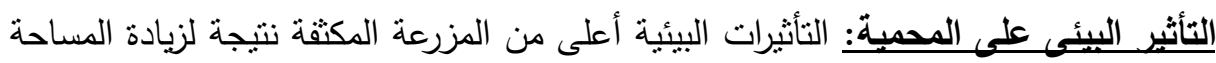
المستزرعة وزيادة كثافة الزريعة عن المعدل المقدم فى الدراسة وذلك لتعويض تكلفة الإنشاءات التى تمت فى مرحلة التجهيز. V-استخراج البترول: تستغل شركة قارون للبترول مساحة تبلغ حوالى 911 آلى فدان تحوى 9

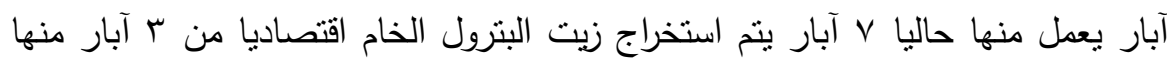

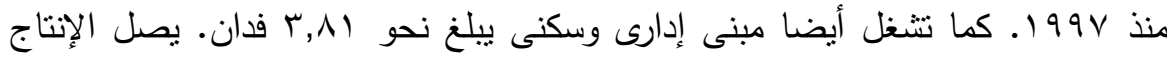

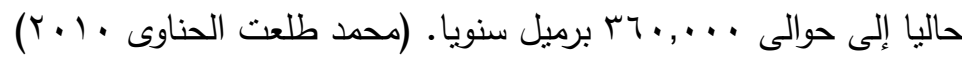

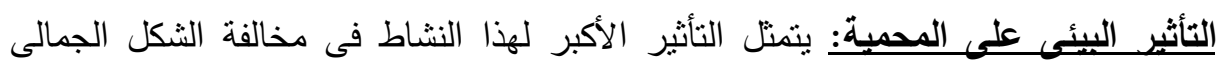
للأرض والقمامة والعبوات الفارغة الملوثة بالزيت الخام. وقد تم ضبط منل هذه المخالفات من لئل قبل حيث قامت إدارة المحمية بإعلام الثركة رسميا بذللك فى حينه وقامت الثركة فورا بإزالة وإصلاح تللك المخالفات على الفور وعلى نفقة الثركة مع تعهد بعدم تكرار منل ذللك. ويتم

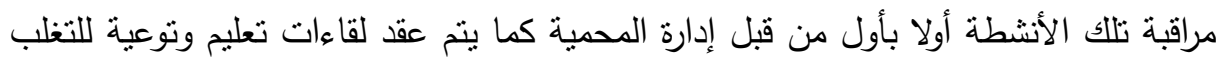

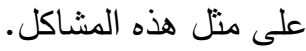


^-التسهيلات السياحية: هناك 7 كافيتريات بمنطقة الزيارة الرئيسية، ؟ منها مملوكة لجهاز

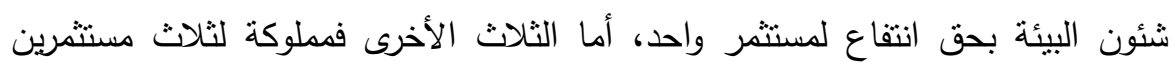
محليين بحق انتفاع للأرض فقط. الثكل الجمالى للكافيتريات الثناثة الأخيرة غير ملائم بالمرة وإن كانت من المواد الطبيعية لذا يجب إعادة تخطيط وإنشاء تلك الكافيتريات. وهناك كامب سياحى بمنطقة الزيارة الرئيسية منوقف عن العمل ولم يصرح جهاز شئون البيئة بكيفية التصرف فيه حيث أنه مديون للجهاز بقيمة حق الانتفاع لسنوات طويلة.

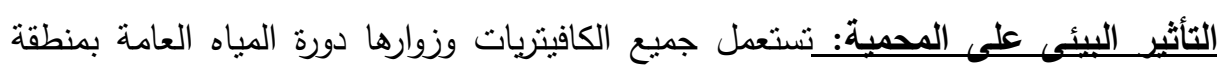
الزيارة والتى تعمل بواسطة خزانات التحليل.

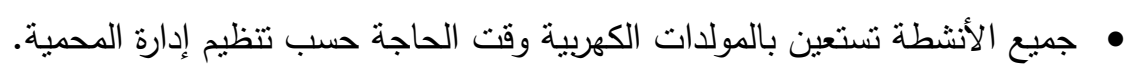

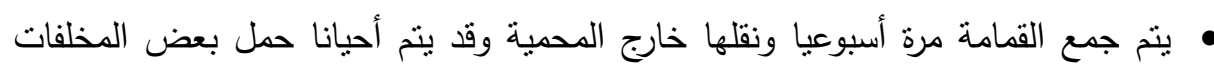

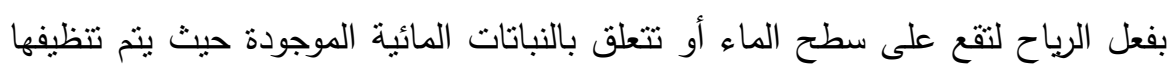
من قبل صاحب النشاط بالتعاون مع إدارة المحمية.(جهازشئونالبيئة - V . . r).

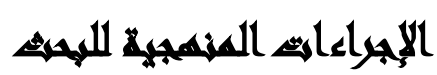

حدود البحث: • الحدود الزمنية: تم جمع الاطار النظرى وبيانات هذا البحث في الفترة من 17 • حتى $r .11$ • الحدود المكانية: تم تطبيق البحث على محمية وادى الريان.

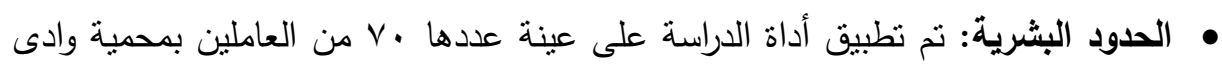
الريان وكذلك من العاملين بجهاز شئون البيئة بوزارة البيئة.

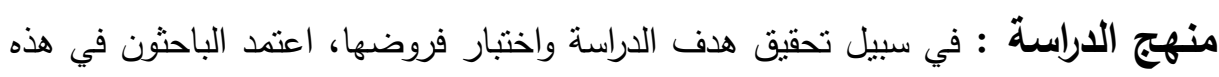

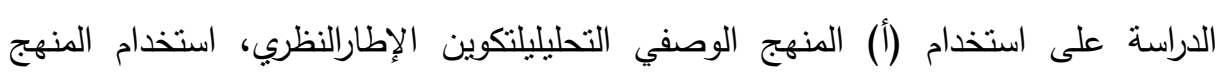
التطبيقي بالتطبيقعلى العاملين بمحمية وادى الريان وجهاز شئون البيئة بوزارة البيئة،واستخدام

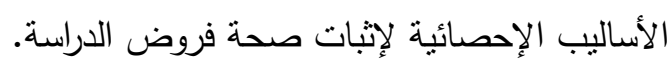


قام الباحثون باستخدام مصدرين أساسين للمعلومات:

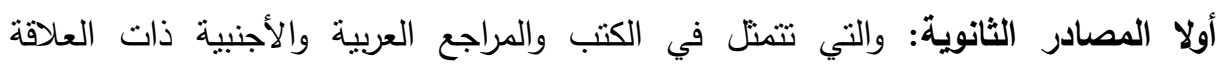

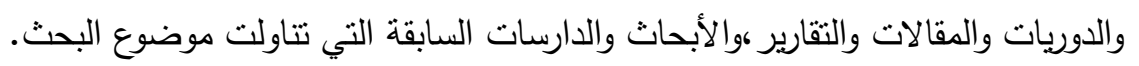

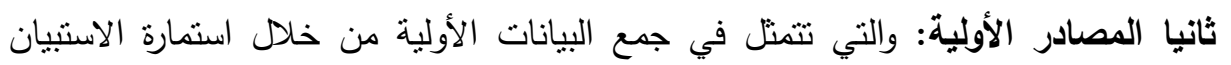

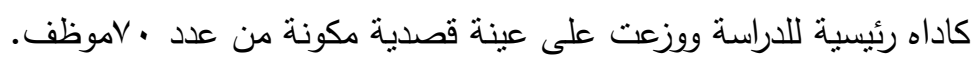
مجتمع البحث: تم تطبيق البحث على العاملين بحمية وادى الريان بإستثناء العمال والحراس والسائقين عينة البحث: عينة قصدية عددها • V والتى تمتل المجتمع الأصلى للبحث وتشمل العاملين بمحمية وادى الريان وعدد من العاملين بجهاز شئون البيئة بوزارة البيئة.

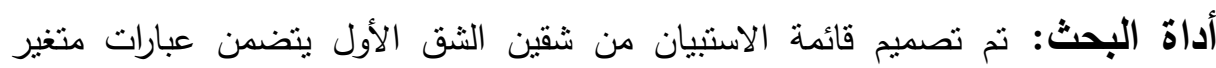

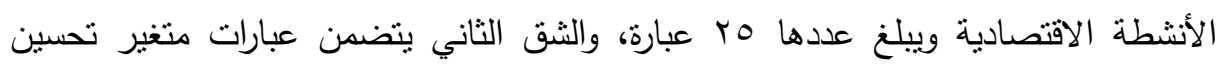
الإدارة ويبلغ عددها مrاعبارة.

ثالثاً وصف أداة الدراسة : نم تصميم قائمة الاستبيان من شقين الثق الأول يتضمن عبارات متغير الأنشطة الاقتصادية ويبلغ عددها مب عبارة، والثق الثاني بتضمن عبارات

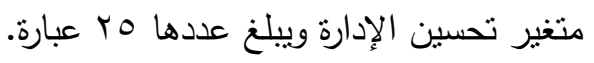

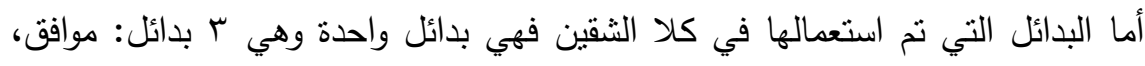
محايد، غيرموافق.هو موضح في الجدول رقم (1). جدول رقم(1 ): درجات مقياس ليكرت

\begin{tabular}{|c|c|c|}
\hline غير موافق & محايد & موافق \\
\hline 1 & $T$ & $r$ \\
\hline
\end{tabular}

وقد تم حساب مستوي الأهمية وفقاً للمعادلة التالية:

$$
\begin{aligned}
& \text { مستوي الأهمية = (الحد الأعلى للإجابة - الحد الأدنى للإجابة) ؛ الحد الأعلى الأعلى للإجابة }
\end{aligned}
$$

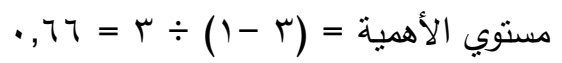


ويناءً على ذلك تكون درجات مستوي الأهمية كما هو موضح في الجدول رقم (r)

\begin{tabular}{|c|c|}
\hline مستوى الأهمية & المتوسط المرجح \\
\hline منخفضة & من ا إلى 77 ا \\
\hline متوسطة & من VT, ו إلى سז, \\
\hline مرتفعة & \\
\hline
\end{tabular}

متغيرات الدراسة:

1- المتغير المستقل: الأنشطة الاقتصادية.

r- المتغير التابع: تحسين الإدارة.

صدق وثبات أداة الدراسة : ويشمل وصف أداة الدراسة علي صدق الاتساق الظاهري وثبات وصدق الاتساق الداخلي لأداة الدراسة وذلك على النحو التالي:

أولاً صدق الاتساق الاخلي: يقصد به مدى اتساق كل عبارة من عبارات الاستبيان مع البعد

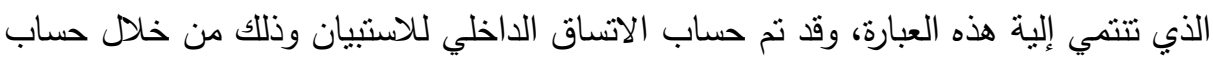
معاملات الارتباط بين كل عبارة من عبارات أبعاد الاستبيان والدرجة الكلية للبعد نفسه.

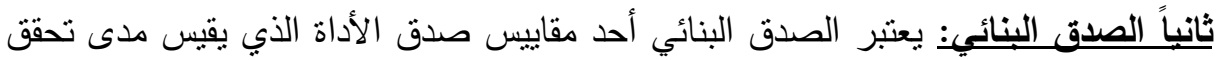

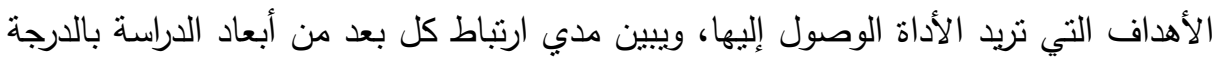
الكلية لعبارات الابعاد.

ثبات الاستيان: يقصد بثبات الاستبيان أن يعطي هذه الاستبيان نفس النتيجة لو نم إعادة

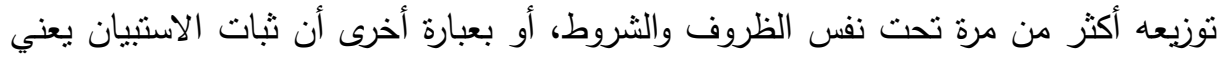

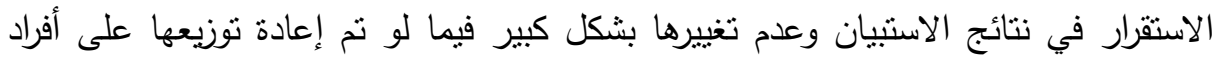
العينة عدة مرات خلال فترات زمنية معينة. وقد قامتالباحثة من التحقق من صدق الاتساق الداخلي والصدق البنائي وثبات الاستنيان من خلال تطبيقه على العينة الفعلية(· V)فرد. نتائج الصدق البنائي: جدول رقم(؟): نتائج الصدق البنائي من خلال معامل ارتباط أبعاد الاستبيان بمجموع الدرجة

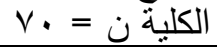

\begin{tabular}{|c|c|c|c|}
\hline الارتباط & \multicolumn{2}{|c|}{ آبعاد الاستيبان } & a \\
\hline$(* *) \cdot, 9 \Gamma q$ & معامل ارتباط بيرسون & الأنشطة الاقتصادية & 1 \\
\hline$\cdot, ., 1$ & الدلالة المعنوية & & 1 \\
\hline$(* *) \cdot, 9 \leqslant \Lambda$ & معامل ارتباط بيرسون & ت & $r$ \\
\hline$\cdot, \cdot 1$ & الدلالة المعنوية & تحسيل الإدارو & \\
\hline
\end{tabular}

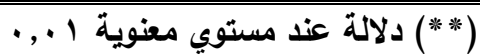

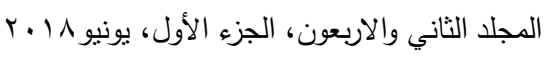


يتضح من الجدول رقم (r) أن جميع الأبعاد ترتبط ببعضها البعض بالدرجة الكلية وهي

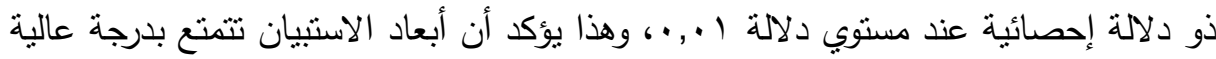

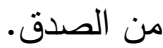
نتائجج ثبات الاستبيان: تم التحقق فالدراسة من ثبات استبيان الدراسة من خلال طريقتن وهما طريقة التجزئة النصفية ومعامل ألفا كرونباخ. أولاً: طريقة التجزئة النصفية: Split-Half Coefficient method: تم استخدام درجات العينة الاستطلاعية لحساب ثبات الاستيان بطريقة التجزئة النصفية، حيث احتسبت درجة النصف الأول لكل بعد من أبعاد الاستنيان وكذلك درجة النصف الثاني من الدرجات وذللك لحساب معامل الارتباط بين النصفين ثم جري تعديل الطول باستخدام معادلة سبيرمان وبراون النصفية المتساوية (Spearman-Brown Coefficient)، ومعادلة جثمان للتجزئة النصفية غير المنساوية (Guttman Split-Half Coefficient) والجدول رقم (؛) يوضح

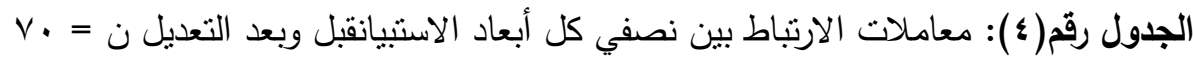

\begin{tabular}{|c|c|c|c|c|}
\hline معامل الثبات بعد & الارتباط قبل & عدد العبارات & الأبعاد & r \\
\hline$\cdot, 90$. & $\cdot, 911$ & ro & الأشطة الاقتصادية & 1 \\
\hline$\cdot, 9 Y 1$ & $\cdot, \wedge 7 \varepsilon$ & To & تحسين الإدارة & r \\
\hline$\cdot, \wedge \vee \mathrm{V}$ & $\cdot, \mathrm{V} \wedge \mathrm{\Lambda}$ & 0. & لي ابعاد الاستبيان & إجد \\
\hline
\end{tabular}

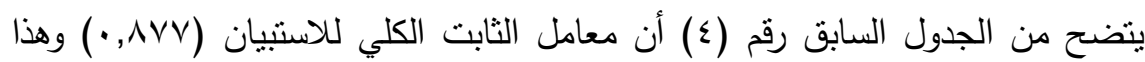
يدل على أن ابعاد الاستبيان تتمتع بدرجة عالية جدا من الثبات.

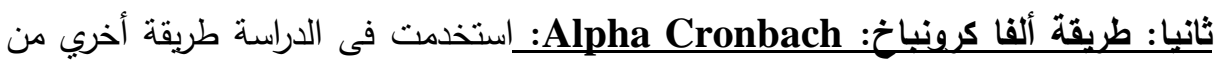
طرق حساب الثبات وهي طريقة ألفا كرونباخ، وذلك بغرض التحقق من ثابت أداة الدراسة،

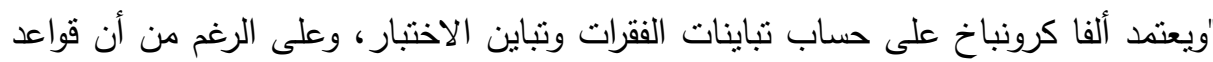

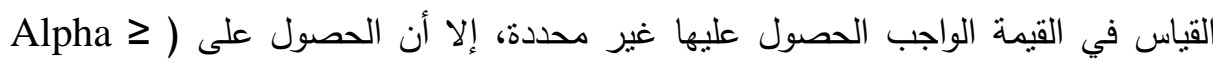
(0.60) يعتبر معقولا. 
الجدول رقم(•): ثبات أبعاد الاستبيان باستخدام ألفا كرونباخ ن =. V

\begin{tabular}{|c|c|c|c|}
\hline كرونباخ آلفا & العبارات & الأبعاد & b \\
\hline$\cdot, 971$ & ro & الانشطة الاقتصادية & 1 \\
\hline$\cdot, 9 \Lambda$. & TO & تحسين الإدارة & $T$ \\
\hline$\cdot, 9 \wedge r$ & 0 . & \multicolumn{2}{|c|}{ إجمالي ابعاد الاستنيان } \\
\hline
\end{tabular}

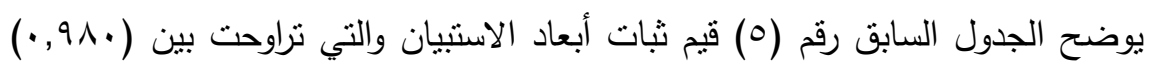

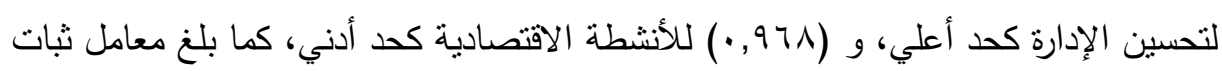

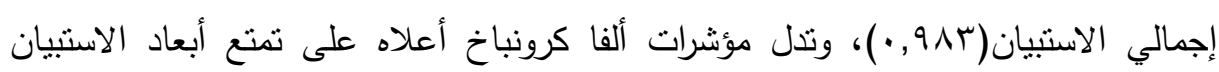
بمعامل ثابت عالٍ وبقدرتها على تحقيق أغراض الدراسة.

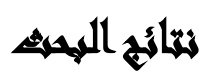

أولاً: نتائج التحليل الوصفي للمتغير المستقل (الأنشطة الاقتصادية). 1 - تحليل عبارات: الأنثطة الاقتصادية.

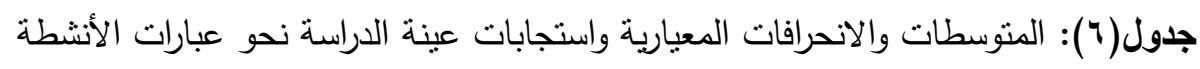

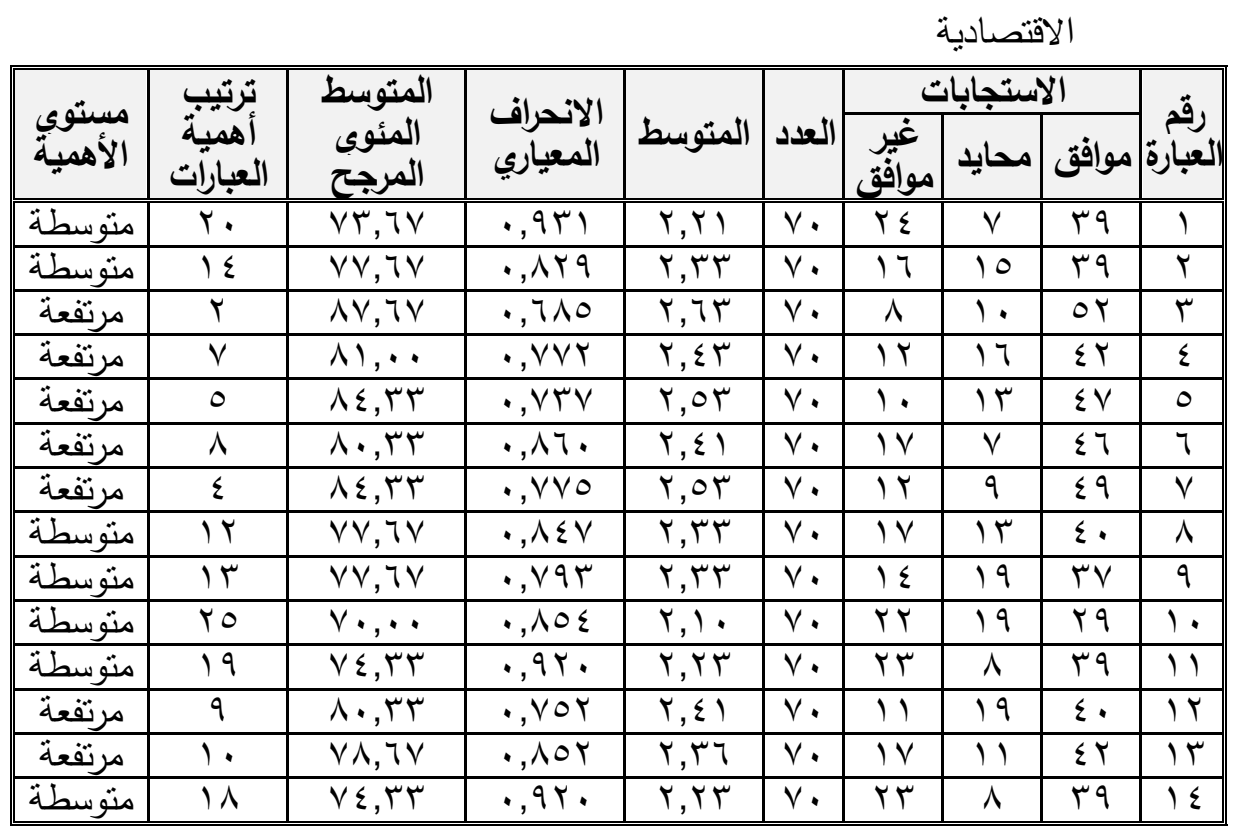

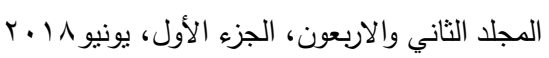


تابع جدول(†): المتوسطات والانحرافات المعيارية واستجابات عينة الدراسة نحو عبارات الأنشطة الاقتصادية

\begin{tabular}{|c|c|c|c|c|c|c|c|c|c|}
\hline \multirow[b]{2}{*}{ الأهميتّة } & \multirow{2}{*}{ أهبية } & \multirow{2}{*}{ المتئوسط } & \multirow[b]{2}{*}{ المعياري } & \multirow[b]{2}{*}{ المتوسط } & \multirow[b]{2}{*}{ العدد } & \multicolumn{3}{|c|}{ الاستجابات } & \multirow[b]{2}{*}{ العبارة } \\
\hline & & & & & & غوافِق & محايد & موافق & \\
\hline مرتفعة & $\bar{r}$ & $\Lambda \varepsilon, 7 V$ & $V \vee \varepsilon$ & T,O & $V$. & 14 & $\Lambda$ & . & \\
\hline متوسطة & $r \varepsilon$ & $V \cdot r T$ & $\cdot, 91$. & $r, 11$ & $\mathrm{~V} \cdot$ & ro & IT & rT & \\
\hline متوسطة & YI & $V T, T V$ & 941 & $r, r)$ & $V$. & $r \varepsilon$ & $V$ & $r 9$ & \\
\hline متوسطة & 10 & $V V, \ldots$ & 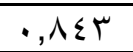 & , I & $V \cdot$ & IV & $1 \varepsilon$ & $r 9$ & \\
\hline متوسطة & IV & $V 0,7 V$ & $\cdot, 917$ & $\overline{Y, Y V}$ & $V \cdot$ & rY & $\mathrm{V}$ & §) & \\
\hline مرتفعة & 7 & הז,r & $\cdot, \mathrm{VOV}$ & $Y, 0$. & $\mathrm{V} \cdot$ & 11 & $1 \pi$ & $\Sigma 7$ & \\
\hline متوسطة & $\pi$ & $V r, \ldots$ & VTV & 19 & $V \cdot$ & 10 & rV & rᄉ & \\
\hline متوسطة & Tr & VI, r & 107 & $1 \leq$ & $V \cdot$ & YI & 11 & $r$ & \\
\hline متوسطة & 17 & $V V, \ldots$ & $\cdot, V \vee Y$ & $r, \Gamma)$ & $V \cdot$ & 11 & rY & ro & \\
\hline مرتفعة & 11 & V^, .. & $\cdot, 1 \vee 09$ & $r, r \leq$ & $V \cdot$ & IT & Yr & $r$ & \\
\hline مرتفعة & 1 & qY,rT &., $0 \leqslant r$ & $r, V V$ & $V \cdot$ & $\varepsilon$ & $\Lambda$ & 01 & \\
\hline \multicolumn{2}{|c|}{ مرتفعة } & $V \wedge, r T$ &., $0 . V$ & T, ro & & - & & 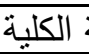 & \\
\hline
\end{tabular}

*تم وضع ارقام العبارات بترتيب وجودها بقائمة الاستبيان في جميع جداول الدارسة.

يُظهر الجدول السابق رقم (؟) المتوسطات الحسابية والاتحرافات المعيارية لاستجابات

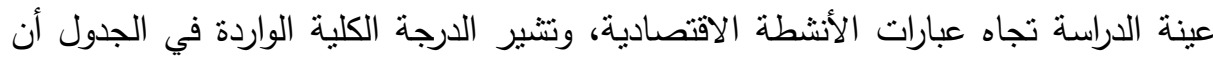

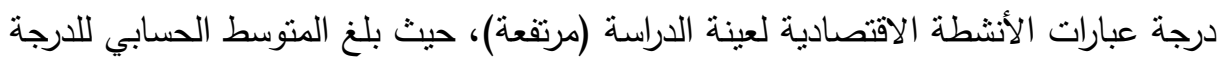

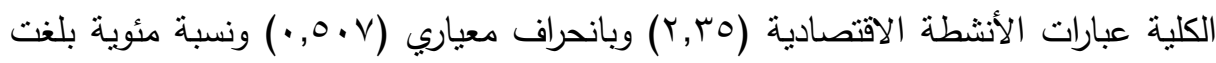

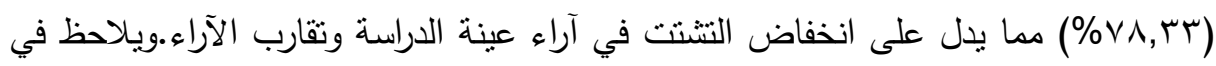

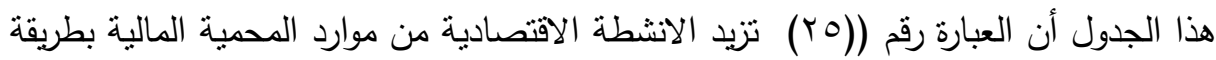

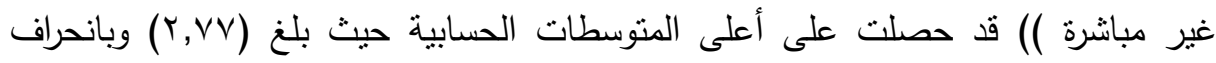

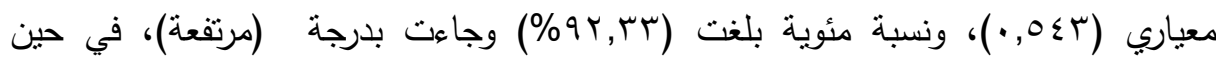

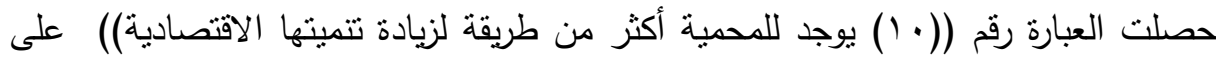

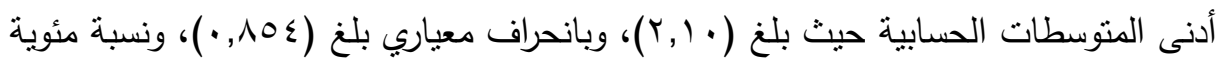

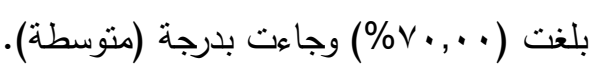


r- تحليل عبارات: تحسين الإدارة. جدول(V): المتوسطات والانحرافات المعيارية واستجابات عينة الدراسة نحو عبارات تحسين الإدارة

\begin{tabular}{|c|c|c|c|c|c|c|c|c|c|}
\hline \multirow[b]{2}{*}{ الأهميتية } & \multirow{2}{*}{ أتربيةت } & \multirow{2}{*}{ المئوسطي } & \multirow[b]{2}{*}{ المعياري } & \multirow[b]{2}{*}{ المتوسط } & \multirow[b]{2}{*}{ 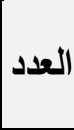 } & \multicolumn{3}{|c|}{ الاستجابات } & \multirow[b]{2}{*}{ |لإعبارة } \\
\hline & & & & & & موأفير & محايد & موافق & \\
\hline متوسطة & $\overline{T \xi}$ & $79,7 \mathrm{~V}$ & 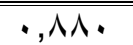 & $Y, \cdot 9$ & $\overline{v .}$ & $r \xi$ & 17 & $\overline{r .}$ & $\overline{11}$ \\
\hline متوسطة & 19 & $V \varepsilon, 7 V$ & $\cdot, \wedge \vee 0$ & $\overline{T, Y \xi}$ & $V^{\prime}$ & $r$. & $\pi$ & $r v$ & $\bar{Y}$ \\
\hline متوسطة & TO & Tr,TV & $\cdot, \wedge \leq \vee$ & 1,91 & $V$. & $r \wedge$ & $r$. & TY & $r$ \\
\hline متوسطة & 10 & $V Y, 7 V$ & $\cdot, \Lambda Y K$ & $r, r$. & $V$. & 17 & IV & $r v$ & $\varepsilon$ \\
\hline متوسطة & YY & $V \cdot r \mu$ & $\cdot, \wedge \varepsilon \Gamma$ & $r, 11$ & $\mathrm{~V} \cdot$ & YI & $r \cdot$ & rq & 0 \\
\hline مرتفعة & $\Lambda$ & $\vee \wedge, 7 \vee$ & $\cdot, 1 \vee 99$ & $r, r q$ & $\overline{v e}$ & $1 \varepsilon$ & IV & rq & 7 \\
\hline مرتفعة & 9 & $\vee \wedge, \cdots$ & $\cdot, \vee \vee 97$ & $T, T \varepsilon$ & $V \cdot$ & $1 \varepsilon$ & 11 & rᄉ & $\mathrm{V}$ \\
\hline متوسطة & $1 \varepsilon$ & $V V, T V$ & $\cdot, \lambda \mid Y$ & Y,T & $V$. & 10 & IV & rᄉ & $\Lambda$ \\
\hline مرتفعة & $\varepsilon$ & $\Delta Y, r T$ & $\cdot, T \vee 0$ & $Y, \Sigma V$ & $V$. & V & Tr & $\varepsilon$. & 9 \\
\hline مرتفعة & $\mathrm{V}$ & $\Lambda \cdot, \cdots$ & $\cdot, 7 \wedge 9$ & T, ६. & $V$. & $\Lambda$ & rq & T & 1. \\
\hline مرتفعة & $r$ & $\Lambda \varepsilon, 7 \vee$ & $\cdot, T \vee \varepsilon$ & $Y, 0 \leqslant$ & $v \cdot$ & V & 11 & $\leqslant 0$ & 11 \\
\hline مرتفعة & $r$ & $\Lambda 0, \mu \mu$ & $\cdot, T \vee \varepsilon$ & r,07 & $v$. & V & IV & $\leq 7$ & 14 \\
\hline متوسطة & 17 & $\vee \tau, r \mu$ & $\cdot, \wedge 19$ & $r, r^{\prime}$ & $V \cdot$ & 17 & 11 & ry & 11 \\
\hline مرتفعة & 7 & $\Delta r, \ldots$ & $\cdot, \vee \vee १ Y$ & $Y, \Sigma Y$ & $V \cdot$ & 11 & $1 Y$ & $\leqslant 0$ & $1 \varepsilon$ \\
\hline مرتفعة & 1. & $\vee \wedge, \ldots$ & $\cdot, \vee \vee \leqslant$. & $r, r \varepsilon$ & $V \cdot$ & 11 & $r \leq$ & ro & 10 \\
\hline متوسطة & 11 & $V \vee, T V$ & $\cdot, \vee 07$ & $r, r \mu$ & $V \cdot$ & 14 & rT & ro & 17 \\
\hline مرتفعة & 0 & $\Lambda Y, r \mu$ & $\cdot, 797$ & $Y, \Sigma V$ & $V_{0}$ & $\Lambda$ & YI & $\leqslant 1$ & IV \\
\hline منوسطة & IV & $\mathrm{VO}, \mathrm{TV}$ & $\cdot, \vee \vee 7$. & $Y, Y V$ & $V_{0}$ & 11 & ro & Tr & 11 \\
\hline مرتفعة & 11 & $\vee \wedge, \ldots$ & $\cdot, \vee 09$ & $Y, T \leq$ & $v_{0}$ & $1 T$ & YY & ry & 19 \\
\hline منوسطة & YI & $V 1, \mu \mu$ & $\cdot, \vee \wedge \wedge$ & $r, I \varepsilon$ & $V_{0}$ & IV & Y7 & TV & $r$. \\
\hline متوسطة & 11 & $\mathrm{VO}, \mathrm{TV}$ & $\cdot, V Y)$ & $\overline{Y, Y V}$ & V. & 11 & rq & $r$. & YI \\
\hline مرتفعة & 1 & $\wedge 0,7 \mathrm{~V}$ & $\cdot, 70$ & $r, O V$ & $V$. & 7 & 11 & $\sum 7$ & TY \\
\hline مرتفعة & IY & $\vee \wedge, \cdots$ & $\cdot, 109$ & $r, r \leqslant$ & $V \cdot$ & IT & KY & $r 7$ & $r T$ \\
\hline متوسطة & r. & $V Y, \ldots$ & $\cdot, \wedge \leq 0$ & $r, 17$ & $V \cdot$ & $r$. & 19 & TI & $T \varepsilon$ \\
\hline متوسطة & rT & $79,7 \mathrm{~V}$ & $\cdot, \wedge \leqslant V$ & $r, .9$ & $V \cdot$ & TY & $r \cdot$ & rA & ro \\
\hline \multicolumn{2}{|c|}{ متوسطة } & $\vee 7,77$ & $\cdot, \Sigma q \mu$ & $r, r \cdot$ & \multicolumn{5}{|c|}{ الدرجة الكلية لتحسين الإدارة } \\
\hline
\end{tabular}

*تم وضع ارقام العبارات بترتيب وجودها بقائمة الاستنيان في جميع جداول الدراسة. 
يُظهر الجدول السابق رقم (V) المتوسطات الحسابية والانحرافات المعيارية لاستجابات عينة الدراسة تجاه عبارات تحسين الإدارة، ونتشير الدرجة الكلية الواردة في الجدول أن درجة

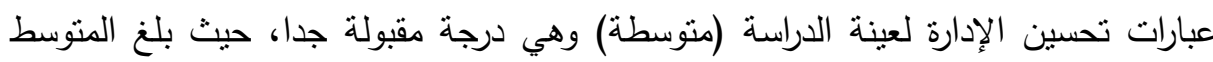

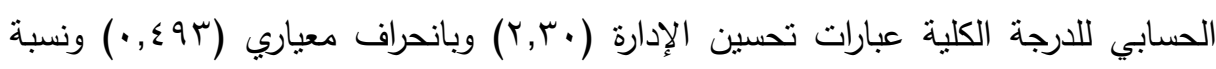

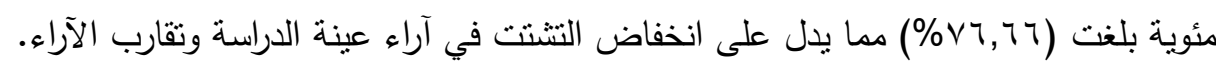

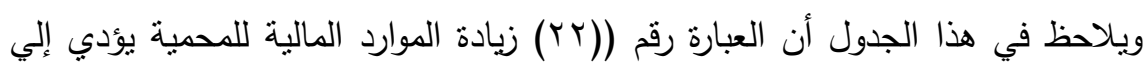
تحسين كفاءة العاملين بها.)) قد حصلت على أعلى المتوسطات الحسابية حيث بلغ (Y,OV)

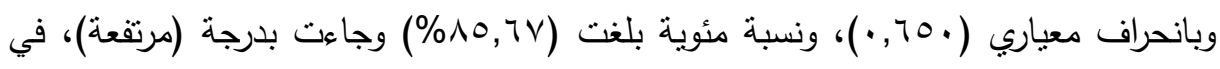
حين حصلت العبارة رقم ((r) تسعى الإدارة إلى تخفيف الروتين والقيود والإجراءات

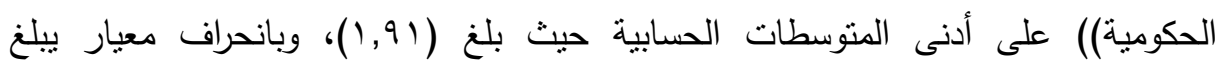

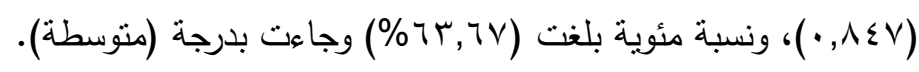

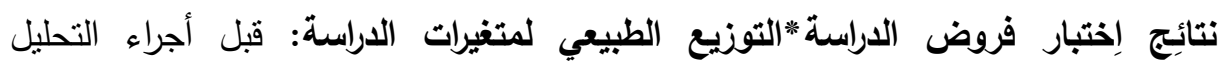

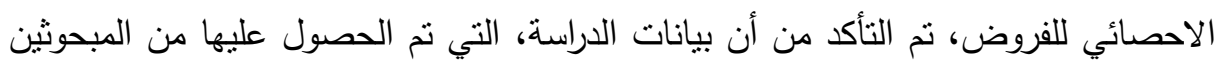

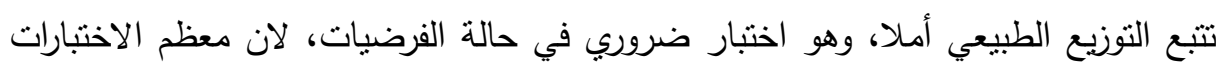

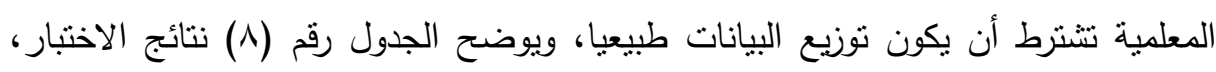

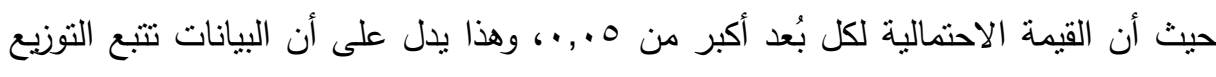
الطبيعي ويجب استخدام الاختبارات المعلمية. جدول رقم(^): نتائج اختبار التوزيع الطبيعي للبيانات التبني

\begin{tabular}{|c|c|c|c|c|c|c|}
\hline \multicolumn{3}{|c|}{$\begin{array}{c}\text { Kolmogorov- } \\
\text { Smirnova }\end{array}$} & \multicolumn{3}{|c|}{ Shapiro-Wilk } & \multirow[t]{2}{*}{ المتغيرات } \\
\hline Statistic & df & \begin{tabular}{|l|} 
Sig. \\
\end{tabular} & Statistic & df & \begin{tabular}{|l|} 
Sig. \\
\end{tabular} & \\
\hline .086 & $\overline{770}$ & $.200 *$ & .975 & $\overline{770}$ & .173 & الآنشطة الاقتصادية \\
\hline .063 & 70 & $.200 *$ & .982 & 70 & .421 & تحسين الإدارة \\
\hline
\end{tabular}

المصدر: من مخرجات برنامج الإدرة 
الفرض الأول: يوجد أثر ذو دلالة إحصائية للأنشطة الاقتصادية و تحسين الإدارة وللتحقق من صحة هذا الفرض قام الباحثون باستخدام الاتحدار الخطي البسيط. جدول رقم(9): نتائج تحليل الانحدار الخطي البسيط فيما يتعلق باختبار الفرض الرئيسي باسئي الأول

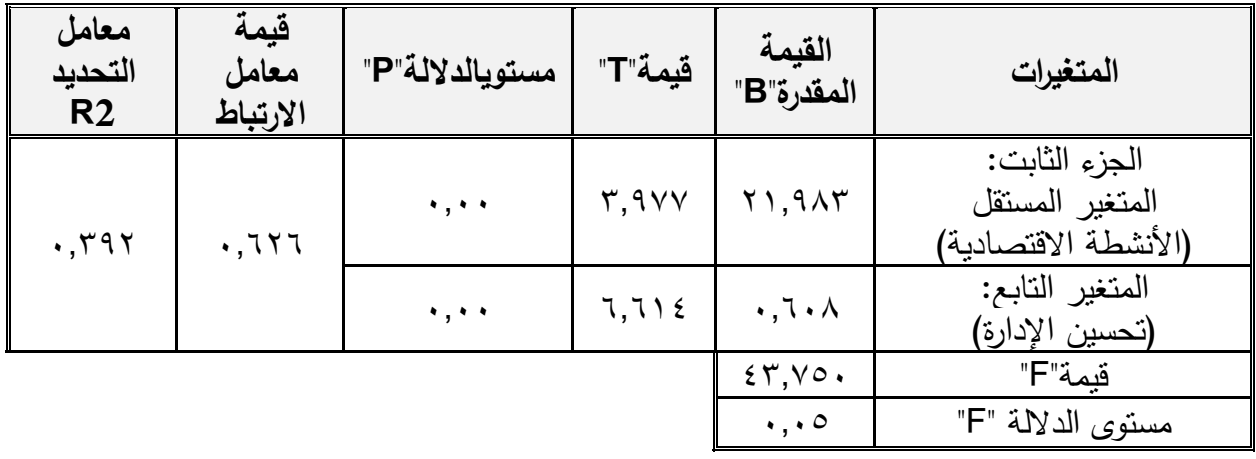

Spss المصدر : من مخرجات برنامج الالة

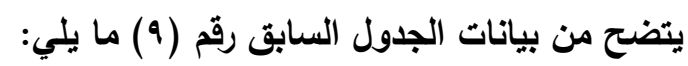

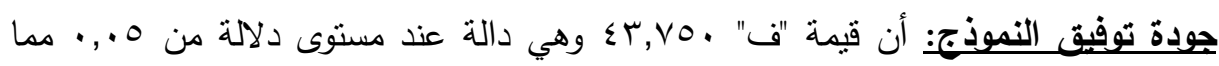
يدل على جودة نوفيق المتغير لنموذج الانحدار وأن المتغير المستقل (الأنشطة الاقتصادية) الاخل في النموذج ذات تأثثر معنوي.

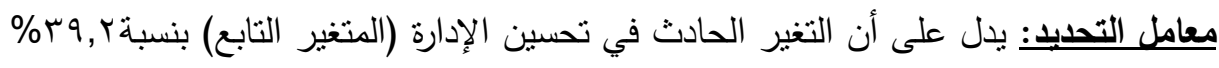

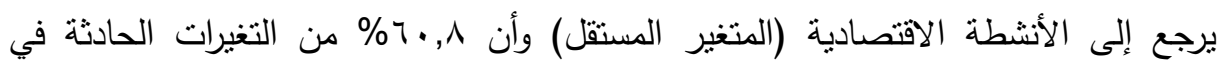

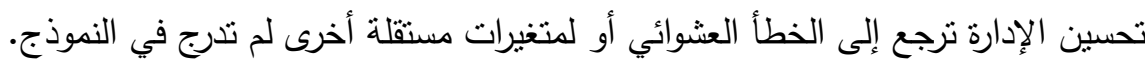
اختبار"ت": يقيس تأثير المتغير المسنقل لوحده في النموذج، وحيث أن مستوى الدلالة (0. . • )

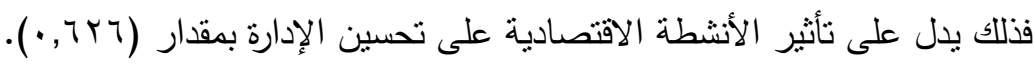

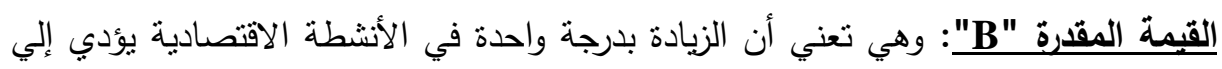
زيادة في تحسين الإدارة بقيمة قدرها (1 • ؟, •).وبالتالي تحقق الفرض الرة الرئيسي الأول القائل يوجد أثز ذو دلالة إحصائية للأنشطة الاقتصادية و تحسين الإدارة. 
الفرض الثاني: توجد فروق معنوية ذات دلالة إحصائية في متوسط استجابات العاملين نحو إدراكهم لأهمية الأنشطة الاقتصاديةوفقا للخبرة الوظيفية والمستوى الوظيفي.

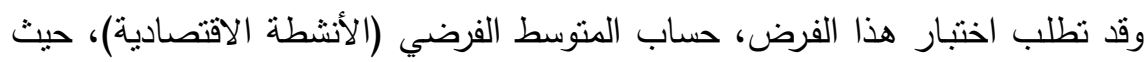

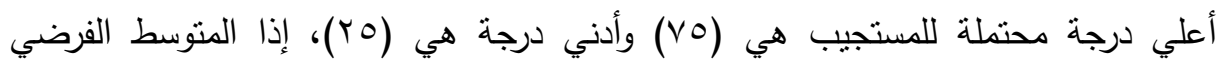

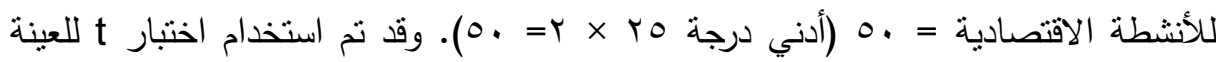
الواحدة (One Sample T test) لتحديد معنوية الفرق بين منوسطات استجابات أفراد

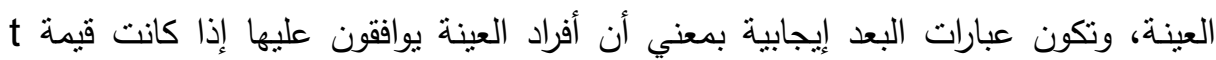

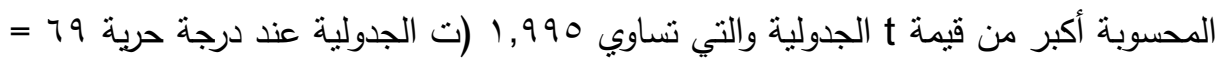

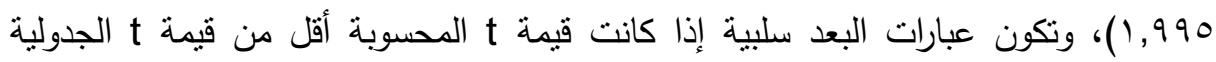

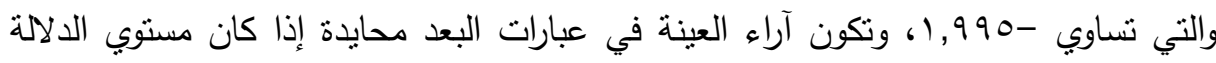
أكبر من ه., •، وفقا لإجابات أفراد عينة الدراسة على عبارات الأنشطة الاقتصادية. جدول رقم(•) (1): نتائج اختبار t للفروق بين استجابات أفراد العينة عبارات الأنشطة

\begin{tabular}{|c|c|c|c|c|c|c|c|}
\hline & & & & \multicolumn{4}{|c|}{ الاقتصادية } \\
\hline مستوية & الحرية & قالجدولية & المَحسوية & الفرضيط & الاتحراف & المتوسط & المتغير \\
\hline$\cdot, .0$ & 79 & 1,990 & 0, VOr & 0. & $14,79$. & $O \wedge, \vee \vee$ & الاقتصنادية \\
\hline
\end{tabular}

المصدر: من مخرجات برنامج Spss من خلال نتائج الجدول السابق (• (1) نجد أن هناك ميل لأفراد عينة الدراسة نحو

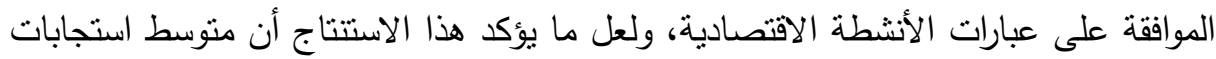

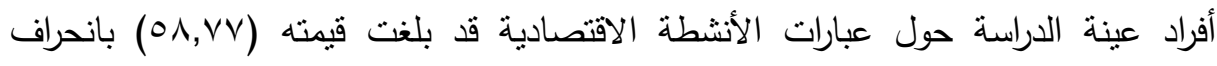
معياري قدره ( • Y,79, ) وهو بذللك أكبر من قيمة المتوسط الفرضي كما بينا سابقاً، كما كانت

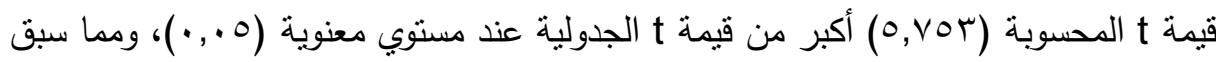
يتضح لنا أن هناك فروق بين المتوسط الفرضي ومتوسط استجابات العاملين نحو إدراكهم للأنشطة الاقتصادية، وكانت الفروق لصالح استجابات العاملين، وبالتالي تحقق الفرض القائل 
بأن: نوجد فروق معنوية ذات دلالة إحصائية في منوسط استجابات العاملين نحو إدراكهم

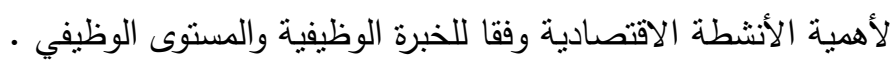

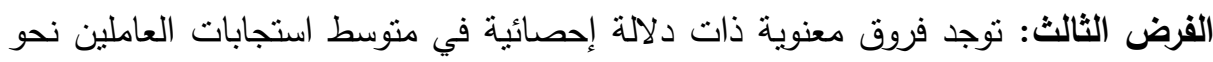
إدراكهم أهمية تحسين الإدارة وفقاً للخبرة الوظيفية والمستوى الوظيفي. دُوني. وقد تطلب اختبار هذا الفرض، حساب المتوسط الفرضي (تحسين الإدارة)، حيث أعلي

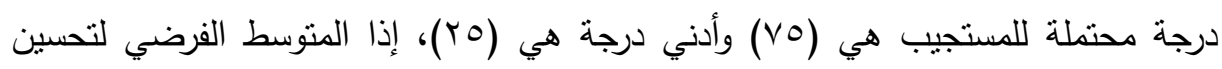

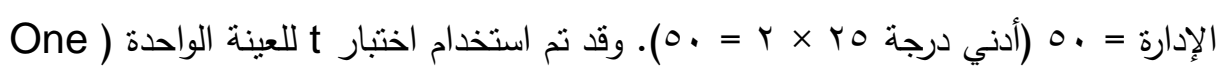
(Sample T test سابقاً. جدول رقم(1 1 ): نتائج اختبار t للفروق بين استجابات أفراد العينة عبارات تحسين الإدارة

\begin{tabular}{|c|c|c|c|c|c|c|c|}
\hline مستوي & الدرجة & قالجدولية & المحسموية & الفرضي المتوسط & الانحراف & المتوسط & المتغير \\
\hline$\bullet, \cdots$ & 79 & 1,990 & $0, Y \leqslant Y$ & 0 . & רוז,זו ו & $0 V, V T$ & تحسين الإدارة \\
\hline
\end{tabular}

Spss المصدر: من مخرجات برنامج الأرة

من خلال نتائج الجدول السابق (1') نجد أن هناك ميل لأفراد عينة الدراسة نحو

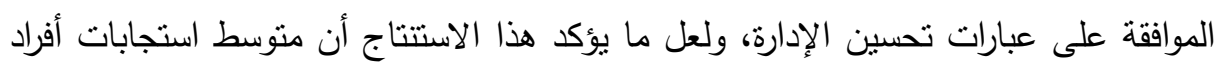

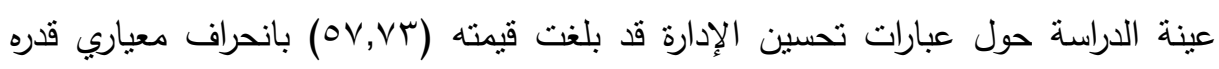

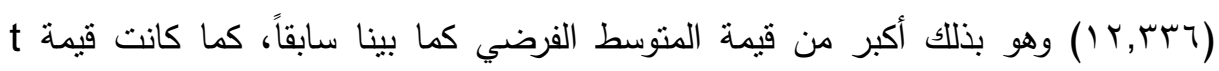

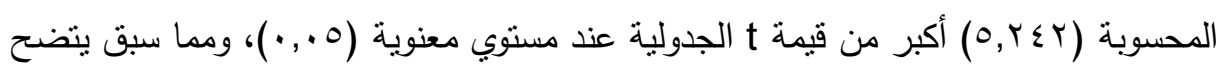
لنا أن هناك فروق بين المتوسط الفرضي ومنوسط استجابات العاملين نحو إدراكهم لتحسين

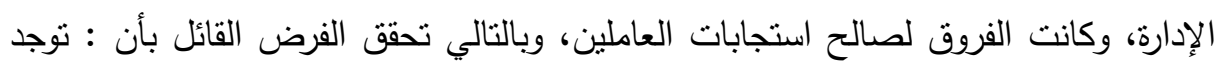
فروق معنوية ذات دلالة إحصائية في متوسط استجابات العاملين نحو إدراكهم أهمية تحسين الإدارة وفقاً للخبرة الوظيفية والمستوى الوظيفي. دلالية إحلئة فئوسيط 
ومن هنا توصل الباحثون لعدة نتائج هامة هى:

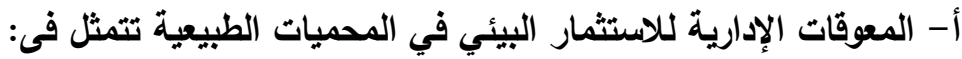

•عدم تتاسب عدد العاملين مع طبيعية الأنشطة . • عدم وجود صيانة دورية للمحميات . • عدم وجود تتسيق بين المؤسسات الحكومية والأهلية . •صعوبة المواصلات في الوصول إلى المحمية . ب- تحسين الإدارة بالمحميات الطبيعية:

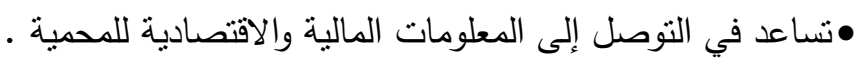
•مساعدة المديرين لاتخاذ قرارات صحيحة وفى الوقت المناسب.

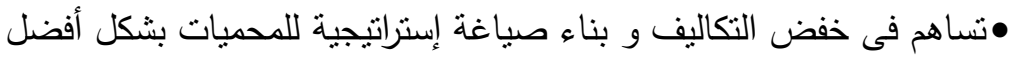
•ترشيد القرارات الإدارية وضمان دقة المعلومات

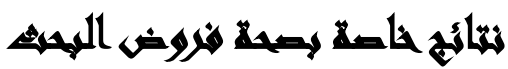

• أن الزيادة بدرجة واحدة في الأنشطة الاقتصادية يؤدي إلي زيادة في تحسين الإدارة بقيمة

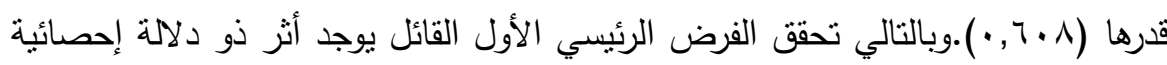
للأنشطة الاقتصادية و تحسين الإدارة. • متوسط استجابات أفراد عينة الدراسة حول عبارات الأنشطة الاقتصادية قد بلغت قيمته (OA,VV) فروق معنوية ذات دلالة إحصائية في متوسط استجابات العاملين نحو إدراكهم لأهمبة باتية

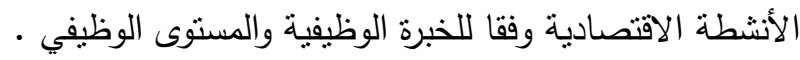
• أن متوسط استجابات أفراد عينة الدراسة حول عبارات تحسين الإدارة قد بلغت قيمته الإنه (OV,VT) فروق معنوية ذات دلالة إحصائية في متوسط استجابات العاملين نحو إدراكهم أهمية تحسين الإدارة وفقاً للخبرة الوظيفية والمستوى الوظيفي. 


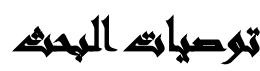 \\ • توصيات خاصة بتمية الاستثمار البيئي في المحميات الطبيعية:}

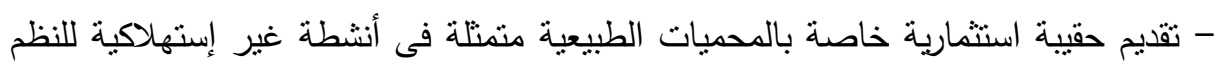
البيئية منل السياحة وتصوير الأفلام والأفلام الوثائقية والزراعة العضوية للنباتات الطبية فئهية

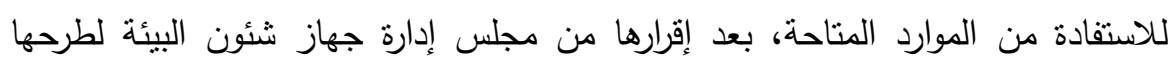

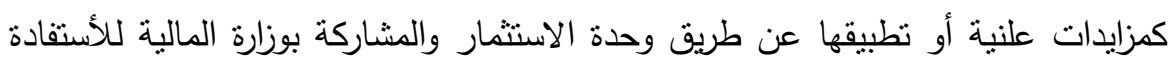
من الموارد المتاحة. - التتسيق مع الوزارات والهيئات والجهات المعنية بشأن المشاريع الإستثماريه التي يمكن تتفيذها بالمحميات.

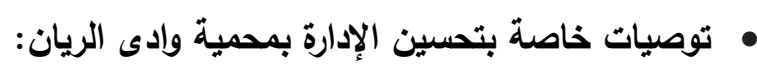

1- تقديم الدعم الكامل لإدارة محمية وادى الريان من حيث القدرات البشرية والمالية والتقنية، من أجل ضمان تحقيق اللإدارة الناجحة والفعالة للحفاظ على الموارد الطبيعية.

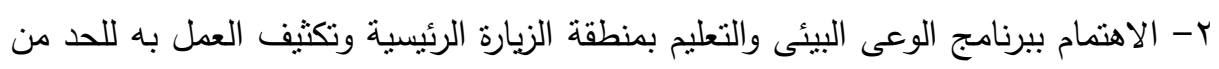
السلوكيات السلبية وتخفيف أثرها على المكان. r- نطوير قاعدة بيانات كاملة ومحدثة عن محمية وادى الريان.

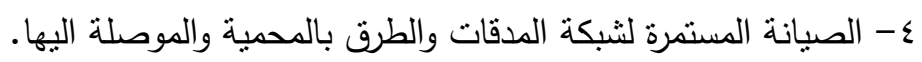
ه- محاولات إثراك المجتمعات الموجودة فى عملية صون الموارد الطبيعية بالمحمية عن طريق توعيتها بأهمية استدامة استخدام الموارد. 4- وضع حوافز للمجتمعات للمشاركة فى البرنامج والعمل على الصون المستدام للموارد (منل

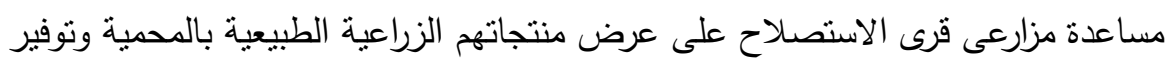

$$
\text { التدريب والمكان المناسب لعملهم). }
$$

V- نوفير روافد دائمة من التمويل لتحديث نظم الحماية بأساليب علمية منطورة والاستفادة بالتكنولوجيا الحيوية وتكنولوجيا المعلومات.

^- تتظيم الدورات التدريبية لتدريب العاملين بالمحمية. 


\section{المرالئ2}

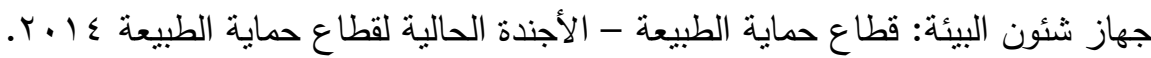

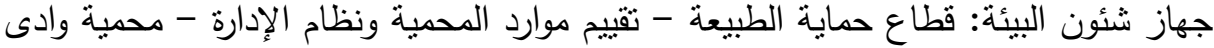

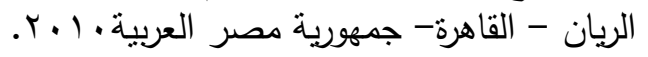

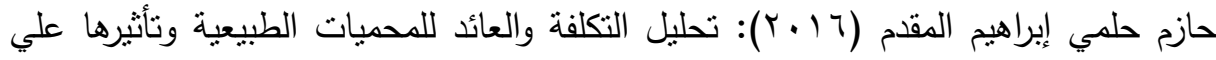
الدخل السباحي بصر (ماجستير) -جامعة المنوفية، كلية التجارة، قسم الاقتصاد والمالية العامة.

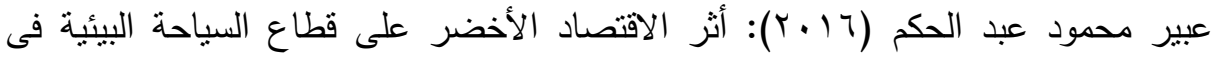

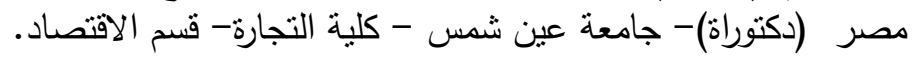

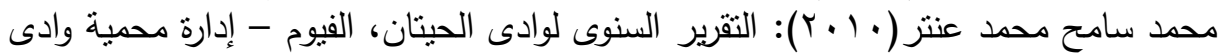

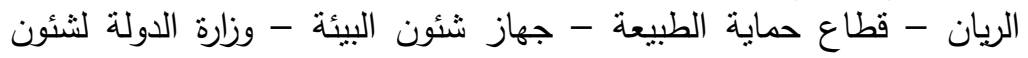

$$
\text { البيئة،. }
$$

محمد طلعت الحناوى( • ( ب): التقرير السنوى محمية وادى الريان - قطاع حماية الطبيعة -

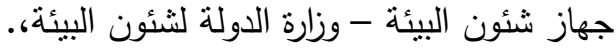

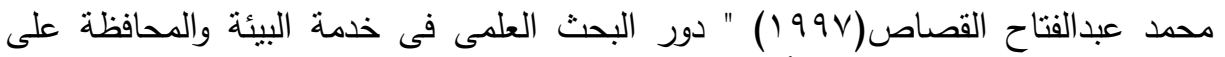

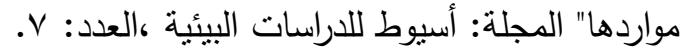

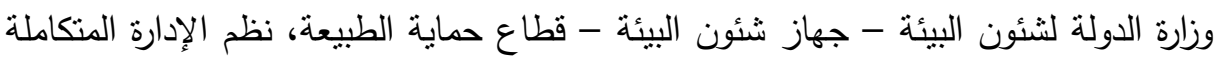

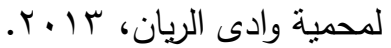

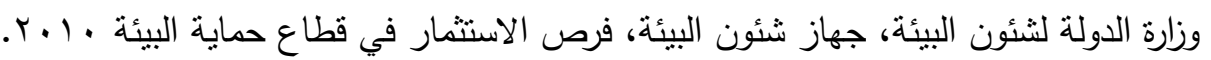

Carneiro, D.; Carvalho,A. (2014) "Payment vehicle as an instrument to elicit economic demand for Conservation" Journal : Ocean \& Coastal Management Vol. 93 p.p.

Chun Maa, Xiaochun Zhang, Weiping Chen b, ${ }^{*}$, Guangyu Zhang a, HuihuiDuanc, MeitingJud, Hongyuan Li d, Zhihong Yang (2013) “China's special marine protected area policy: Trade-off between conomicdevelopment and marine conservation" Journal: Ocean \& Coastal Management Vol. 76 
جمال سعد خطاب وآخرون

Mohamed A. Abdrabo(2015) : Mahmoud A. Hassaan - Economic valuation of Wadi El Rayan Protected Area - the Egyptian Environmental Affairs Agency (EEAA) and Nature conservation Sector.

SuvaluckSatumanatpan a, PisaseSenawongse b, WeranitThansuporn c, Hugh Kirkman d (2014) "Enhancing management effectiveness of environmental protectedareas, Thailand" Journal: Ocean \& Coastal ManagementVol. 89 .

\title{
UTILIZATION OF ECONOMIC ACTIVITIES TO IMPROVE THE MANAGEMENT OF WADI EL- RAYAN PROTECTED AREA
}

\author{
Khatab, G. S. ${ }^{(1)}$; El-Shahat, Nehal, M. F. ${ }^{(2)}$; Mohamed, Kh. A. ${ }^{(3)}$ \\ and Abou bakr, Doaa,
}

1) Faculty of Commerce, Ain Shams University 2) Institute of Environmental Studies \& Research, Ain Shams University 3) Ministry of Environment

\begin{abstract}
The aim of this study is to identify how economic activities can be used to improve the management of the Wadi El Rayan protected area, and to find the relationship between economic activities and increase the income allocated to protected areas to spend on various management activities in light of the lack of available financial resources. On natural resources for sustainable development. In order to achieve this, the researchers designed a questionnaire form distributed to a sample of 70 employees (officials, environmental researchers, employees, accountants and legal specialists) in Wadi El Rayyan and the Environmental Affairs Agency at the Ministry of Environment.
\end{abstract}

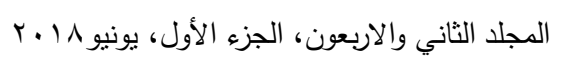


The study found that the change in management improvement (dependent variable) by $39.2 \%$ was due to economic activities (independent variable) at a level of significance of (0.05). The study reached a number of recommendations, the most important of which is: that the resources of protected areas should be spent on the development of protected areas and reduce dependence on the government budget.

As well as work on providing a portfolio of natural reserves to benefit from the available resources, after approval by the Board of Directors of the EEAA for public auctions or application through the Investment and Participation Unit of the Ministry of Finance. And coordination with ministries, agencies and concerned bodies on investment projects that can be implemented in the reserves. As well as work on the development of eco-tourism programs within the reserves to achieve self-financing and sustainable. 